\title{
Cleft Maxillary Hypoplasia
}

\author{
Philip Mathew, Mustafa. K, and Paul Mathai
}

\subsection{Introduction}

Studies of adult patients with unoperated cleft lip and palate (CLP) indicate that the maxilla in the unoperated patient is normally positioned or protruded. There are two major factors contributing to the protruded maxilla. The first is the absence of normal functional forces that are provided by the perioral muscle and tissue continuity. The tongue pressure pushes the teeth and the alveolus forward while the pressure from the cleft lip and affected perioral tissues is insufficient to balance this force out. The second factor contributing to the prognathic maxilla is the missing surgical scar [1-3].

Studies comparing unoperated cleft lip cases versus those with cleft lip repair show minimal difference in the growth of the maxilla. Thus, it has been proven that cheiloplasty has little effect on the growth of the maxilla and its dentition. On the other hand, palatal surgery has been identified as the main cause of inhibition of midface growth. Scar tissue forms across sutural areas as a result of palatoplasty surgery. This scar tissue interferes in the downward and forward translation of the maxilla that plays a major role in normal development. Furthermore, the scar tissue across the palate

Disclosures: The authors have no financial conflicts to disclose

Electronic Supplementary Material The online version of this chapter (https://doi.org/10.1007/978-981-15-1346-6_75) contains supplementary material, which is available to authorized users.

P. Mathew $(\square)$

Head of Department of Oral and Maxillofacial Surgery, Jubilee Mission Medical College and Hospital, Thrissur, Kerala, India

Mustafa. K

Department of Craniofacial Surgery, Kanachur Institute of Medical Sciences, Mangalore, Karnataka, India

P. Mathai

Senior Resident cum Fellow of Orthognathic Surgery, Department of Oral and Maxillofacial Surgery, Jubilee Mission Medical College and Hospital, Thrissur, Kerala, India causes the constriction of the maxilla leading to a collapsed bite or crossbite [1-3].

Maxillary hypoplasia is a secondary deformity that occurs as a result of cleft lip and palate surgery with a reported incidence of about $9-45 \%$ with isolated cleft lip cases having the lowest incidence. The need for surgical correction of the same can be identified as early as age 10. Factors frequently associated with maxillary hypoplasia are congenitally missing maxillary teeth, revision palatoplasty procedures, pharyngeal flaps, and delayed orthodontic care [4-7]. However, recent evidence has suggested that presence of a pharyngeal flap does not affect maxillary growth [8].

\subsection{Features of Cleft Maxillary Hypoplasia}

Cleft maxillary hypoplasia presents as a three-dimensional deficiency. The degree of deficiency increases with the severity of orofacial clefting and affects different anatomical subunits, e.g., dentoalveolar, para-nasal, infra-orbital, and zygomatic regions. The clinical features associated with cleft maxillary hypoplasia are described in Boxes 75.1-75.3 [1-3, 7].

The presence of the cleft alveolus causes the dentoalveolar segment to collapse palatally on the affected side(s) leading to the creation of anterior and posterior crossbites. The failure to perform an alveolar bone grafting and orthodontics during the growing phase increases the severity of the malocclusion [9, 10]. The extent of this abnormal growth of the midface varies from mild to severe and is also affected by genetic endowment, the severity of clefting (extent of orofacial and labio-palatal involvement), timing of surgery, surgeon skills, and the number of primary and revision surgeries performed in the process of re-habilitating the patient. It has not been conclusively proven if any particular palate closure technique or if a staged technique has reduced effects on maxillary growth. It is the author's opinion that techniques that leave a raw area on the palate like pushback palatoplasty are generally associated with greater maxillary regression [1-3, 11-15]. 
Box 75.1: Primary Features of Cleft Maxillary Hypoplasia

- Concave facial profile

- Class 3 skeletal relationship,

- Increased scleral show,

- Lack of normal cheek contour,

- Inadequate support of nasal tip and upper lip,

- Short upper lip and Acute nasolabial angle [subject to variability],

- Steep mandibular plane angle,

- Retruded chin,

- Decreased posterior facial height,

- Increased anterior facial height,

- Anterior and posterior cross bites,

- Increased mandibular plane - cranial base angle,

- Anterior open bite [less common],

- Chin and mandibular skeletal asymmetry [less common].

\section{Box 75.2: Secondary Residual Deformities in Cleft Lip and Palate Patients}

- Speech and hearing impairments (chronic otitis and velopharyngeal insufficiency)

- Residual oronasal fistula

- Residual bony defects

- Obstructive nasal breathing (septum deformity/ enlarged inferior turbinates/intranasal strictures/ enlarged tonsils and adenoids/pharyngeal flaps)

\section{Box 75.3: Dental Anomalies in Cleft Lip and Palate}

Patients

- Delayed eruption of teeth, severe crowding of arches (with impacted, malformed and supernumerary teeth)

- Palatally collapsed dentoalveolar segments (cleft side)

- Anterior and posterior crossbites

- Anomalous or missing lateral incisor, infra-erupted, rotated, and tipped cleft-adjacent teeth

In most cases, photographic and cephalometric analysis reveals that the mandibular plane-cranial base angle is increased leading to a more backwardly placed mandible. Thus, the mandible tends to have a mild retrognathic appear- ance in spite of having normal dimensions. An anterior open bite is observed if the patient has an underlying tongue thrust habit as well. In certain rare cases, the chin and mandible may also exhibit a degree of skeletal asymmetry [1-3] (Box 75.2).

The need for orthognathic surgery should be based not only on occlusion and jaw relationship but also on facial proportions, midface projection, and complaints of the patient [1-3].

\subsection{Objectives of Treatment (Box 75.4)}

\section{Box 75.4: Objectives of Treatment in Cleft Maxillary Hypoplasia}

1. To improve facial aesthetics

2. To improve psychological health

3. Achieve adequate occlusion for efficient mastication

4. Improve phonation and airway dimensions

5. Avoid deterioration of velopharyngeal insufficiency

\subsection{Sequencing Treatment in CMH (Box 75.5)}

Box 75.5: Sequencing Treatment in $\mathrm{CMH}$

1. Growth modulation-7-16 years.

2. Phase 1 orthodontics - 7-11 years

3. Alveolar bone grafting-8-11 years

4. Phase 2 orthodontics-12-17 years

5. Anterior maxillary distraction-after 12 years

6. Orthognathic surgery at 17 years and up

7. Phase 3 orthodontics after orthognathic surgery

\subsection{Orthodontics in Cleft Lip and Palate Patients}

Owing to the severity of the condition, period of orthodontics can be prolonged and is carried out in three phases. Sometimes patients with CLP have a limited ability to open their mouth further increasing the difficulty of orthodontic treatment.

Phase 1 Treatment It is carried out between 7 and 12 years of age. Maxillary transverse expansion is carried out in cases 
that present with maxillary constriction. Maxillary protraction may be carried out in cases with significant midface regression. This phase also involves monitoring facial growth, space management, monitoring eruption of permanent teeth, and preventing ectopic eruption of permanent teeth [1-3].

In preparation for secondary alveolar bone grafting, extractions of supernumerary teeth and deciduous teeth on either side of the cleft and closure of oronasal fistulae are performed [16]. Box 75.6 outlines the controversy regarding whether maxillary expansion should be performed before or after alveolar bone grafting [17-19].

\section{Box 75.6: Arch expansion, before or after Alveolar Bone Grafting (ABG)}

Expansion before $\mathrm{ABG}$

Greater expansion can be achieved with the lower bony resistance between the maxillary segments

Nasal floor mucosa layer can be easily visualized and reconstructed as the cleft has been widened

Widening of the cleft alveolus leads to increased tension on the overlying suture site after grafting, which increases the risk of wound dehiscence and graft failure

Increased risk for cleft-adjacent teeth moving into the cleft alveolus while widening, thus compromising their periodontal support

Clinical studies have shown that there is minimal risk for graft loss when expansion was performed before grafting
Expansion after ABG

Though expansion is possible, the degree of expansion obtained is less predictable

Difficult to visualize and reconstruct the nasal floor mucosa layer as the cleft is narrow

As the cleft is narrow at the time of grafting, there is lesser tension on the overlying suture site after grafting, which reduces the risk of wound dehiscence and graft failure

Decreased risk of loss of periodontal support as the teeth will move into an already grafted cleft alveolus

Clinical studies have shown that bone graft was not lost when expansion was performed after grafting; instead, some degree of stimulation of graft took place and cannot be accommodated, proclination of maxillary incisors, and retraction of mandibular incisors.

In case the skeletal discrepancy is moderate to severe, then we will have to consider surgical correction (distraction osteogenesis or orthognathic surgery) of the deformity. Presurgical fixed orthodontics is started to facilitate the planned skeletal movements and is described in Box 75.7.

\section{Box 75.7: Objectives of Pre-surgical Orthodontics}

- Removal of dental compensations

- Alignment of teeth, de-crowding and de-rotation of teeth

- Flattening of the curve of Spee

- Incorporating divergence in roots for segmental osteotomies

- Co-ordination of dental arches

In case the lateral incisor is missing, the decision to maintain space for prosthetic rehabilitation or substitute it with the adjacent canine needs to be made during this phase [1-3]. There is also a need to extract the mandibular third molars in case a bilateral sagittal split osteotomy is planned. There is an increased risk for bad splits associated with un-erupted and impacted mandibular third molars in the age group of less than 20 years on account of thinner and immature cortical bone [20].

Phase 3 (Postsurgical Phase) Treatment It is performed after surgical correction of the facial deformity (orthognathic surgery or distraction osteogenesis). It involves fine-tuning of the occlusion and maintaining achieved results in the long term through retentive appliances. One may have to consider re-creating dental compensations to accommodate for increased rates of relapse after cleft-orthognathic surgery.

\subsection{Considerations Before Surgery}

\subsubsection{Timing of Surgery}

between 12 and 17 years of age. It involves maintaining the previously attained expansion and further expanding the arch in cases of relapse or if no prior expansion was done. In case the skeletal discrepancy is minimal, we can also consider camouflage orthodontics to correct the occlusal discrepancy. Camouflage orthodontics involves correction of crowding and rotations, extraction of teeth that have erupted ectopically
Facial growth is normally completed by 16 years of age in females and by 17 years of age in males. It is advisable to perform orthognathic surgery only after skeletal maturity is achieved, in order to increase stability of the surgical results in the long term. In selective cases, orthognathic surgery is performed during growth for psychosocial or functional rea- 
sons. However, this has shown unpredictable results because of continued growth of the mandible with relapse rates in the range of $50-70 \%$ when operated before 18 years of age [2, 21, 22].

As an alternative, one may consider distraction osteogenesis prior to 17 years of age. A study by Meazzini et al. [23] reported a relapse rate of $26 \%$ in the long term when distraction osteogenesis of the maxilla was carried out during the growing phase. A systematic review by Liu et al. [24] reported a relapse rate $12-46 \%$ at "point $A$ " and $26-77 \%$ for the SNA angle in the long term. Thus, the patient will require additional surgery after skeletal maturity for correction of the residual facial deformity, irrespective of whether distraction osteogenesis or orthognathic surgery was performed.

\subsubsection{Status of Alveolar Bone Grafting and Oronasal Fistulae}

Patients with cleft lip and palate usually present with a cleft alveolus. This cleft communicates with the nasal cavity, thus, creating an oronasal fistula. The cleft is also a source of weakness in the maxillary arch and increases the risk of arch collapse, thus, creating dentoalveolar deformities (e.g., crossbites) which make later surgical procedures like orthognathic surgery unstable. Lastly, the permanent teeth that erupt into the cleft will have a poor prognosis due to lack of bony support and inadequate periodontium. Thus, it is of utmost importance to graft the cleft alveolar region, and the benefits associated with it are described in Box $75.8[9,25]$.

\section{Box 75.8: Benefits of Alveolar Bone Grafting}

Reduction of oronasal fistula, creation of continuity of the maxillary alveolar arch, eruption of permanent teeth into the cleft site, elevation of the alar nasal base, and stability for future surgical procedures like orthognathic surgery and rhinoplasty
There are three possible treatment protocols that we can follow:

1. The patient is willing to undergo a staged approach with alveolar bone grafting followed by orthognathic surgery at later stage. Though this is the ideal approach, it adds to the cost and time of overall treatment. It is important to note that tertiary alveolar bone grafting has an overall lower success rate [26, 27].

2. The patient is willing to undergo alveolar bone grafting as long as it is done simultaneously with orthognathic surgery. This approach saves time and cost of overall treatment. Keeping in mind that tertiary alveolar bone grafting already has a lower success rate; it is the author's opinion that risk for graft failure might increase when this step is combined with orthognathic surgery. This is on account of the compromise in vascularity that occurs as extensive mucoperisoteal flap refelction is performed to accomodate orthognathic surgery.

3. In case the patient wants to avoid bone grafting, one can use the modified LeFort I osteotomy approach by Posnick et al. [3, 28, 29]. It allows for simultaneous correction of maxillary hypoplasia, cleft dental gaps, alveolar defects, and small residual oronasal fistulas through the use of modified skeletal osteotomies. The cleft alveolar defect is closed by differential repositioning of the cleft maxilla segments. This technique requires a transverse plate to be placed across the cleft site just below the pyriform aperture so as to convert the cleft-maxilla into a single unit. In a study by Posnick et al. [30], the modified LeFort I osteotomy technique had stable results in more than $90 \%$ of the subjects at 1 year with a low complication rate. It is the author's opinion that along with the midline transverse plate, one can also use a dental prosthesis (fixed partial denture) spanning the cleft alveolus site to add stability to the cleft maxilla. However, there is a risk for failure of the prosthesis and loss of abutment teeth in the long term due to increased movement across the cleft alveolus site.

\subsubsection{Velopharyngeal Insufficiency (VPI)}

If air or sound is allowed to leak through or resonate in the nasal cavity during the production of the non-nasal sounds (all phonemes except $/ \mathrm{m} /, / \mathrm{n} /$, and $/ \mathrm{ng} /$ ), speech will be marked by hyper-nasality (nasal twang) and nasal air emission. VPI describes a structural or anatomic defect that prevents closure of the velopharyngeal mechanism during function. It is most commonly observed in patients with an overt cleft palate (unoperated $>$ operated cases) and submucous cleft palate. In operated cleft palate patients, the incidence of VPI can range between 20 and 50\% [31]. Chua et al. [32] and Pereira et al. [33] proposed the usage of perceptual speech assessment, acoustic measurement with this clinical scenario, the difficulty of the surgical procedure increases significantly as the maxilla is not a single unit. 
nasometer, video nasoendoscopy (or video fluoroscopy), and cephalometric analysis for the assessment of preoperative speech and VPI.

When the maxilla is advanced in operated cases of the cleft palate, speech articulation is improved on account of improved lip competency and correction of previous dental malocclusion $[34,35]$. There is also an associated increase in the velopharyngeal cavity depth [36]. As compared to the normal palate, the scarred cleft palate has decreased ability to adapt to such changes as it is unable to stretch adequately [37] This leads to an increase in the risk for worsening of preoperative VPI. The effect of maxillary advancement on VPI, especially in cleft palate patients, is still a controversial topic [34, 38].

There are two methods that are commonly used to advance the maxilla as given in Box 75.9.

\section{Box 75.9: Methods Used for Maxillary Advancement}

1. Distraction osteogenesis: total maxillary distraction and anterior maxillary distraction

(a) Total maxillary distraction: internal maxillary distraction and rigid external distraction

2. Conventional orthognathic surgery

The theoretical advantage of distraction is that the maxilla is advanced slowly which allows the patient to adapt to the changes in the velopharyngeal dimensions through increased velar muscle activity. Furthermore, distraction can be halted at any point of time that speech begins to deteriorate. Orthognathic surgery, unlike distraction, creates an immediate surgical advancement of the maxilla and does not allow speech to be assessed incrementally or allow for gradual adaption of the palate to the increase in the velopharyngeal cavity depth.

A randomized controlled trial by Chua et al. [32] for moderate maxillary advancement $(4-10 \mathrm{~mm})$ in cleft patients demonstrated that distraction osteogenesis had no advantage over orthognathic surgery for the purpose of preventing velopharyngeal incompetence and speech disturbance. Furthermore, no correlation was found between the amount of advancement and speech parameters. However, it should be noted that extreme advancements of the maxilla (greater than $10 \mathrm{~mm}$ ) were excluded from the study.

A study by McComb et al. [37] helped identify predictors for worsening of VPI in cases of cleft maxillary advancement using conventional orthognathic surgery. Short preoperative soft palate, large postoperative velopharyngeal cavity depth, preoperative perceptual speech assessment, nasometry, and video nasoendoscopy were identified as clinically significant predictors. Preoperative velopharyngeal cavity depth was not considered a satisfactory predictor as changes in the velopharyngeal space did not correspond proportionally to maxillary advancement [39]. Lastly, the span of maxillary advancement $(2-16 \mathrm{~mm})$ did not show a significant association with the worsening of VPI [37].

Janulewicz et al. [35], Philips et al. [40], Alaluusua [41], Smedberg [42], Seok-Kwun Kim et al. [43], Kelly Schultz et al. [44], and Pereira et al. [33] studied the relation between postoperative worsening of VPI and maxillary advancement using conventional LeFort I osteotomy in cleft patients. They established that preoperative borderline and higher grades of VPI were highly prone to worsening in the postoperative phase. Absent to negligible VPI pre-operatively, carries minimal risk of worsening during the post-operative period. Furthermore, the amount of maxillary advancement and the cleft type did not influence the degree of worsening of VPI. In the author's opinion, the only confounding factor in the above studies was that some of the patients already had a preoperative pharyngeal flap.

A study by Trindade et al. [45] suggested that deterioration in the VPI after orthognathic surgery was transient and improved over time. Compensatory changes are known to occur in the velopharyngeal region during that time as documented by the study of Yu Wu et al. [36]. The velar length and angle and the velopharyngeal depth all increased. However, velar thickness, posterior pharyngeal wall thickness, and velar motility remained unchanged. During certain phonations, the motion of the posterior pharyngeal wall and the thickness of the Passavant's ridge increased significantly. Thus, it is advisable to wait for at least 1 year prior to considering surgical correction for VPI [35].

Poole et al. [46] and James et al. [47] suggested alternative surgical approaches to the routine LeFort I maxillary advancement which involved transecting the palatal mucosa followed by mobilizing the soft palate lying distal to the incision. This was combined with strategically placed vertical incisions in the maxillary buccal mucosa to avoid circulation injury. The advantage of the procedure was that the maxilla could be advanced by large amounts without worsening of speech and VPI as the soft palate did not move anteriorly with the maxilla. The disadvantage of the procedure was that a significant portion of the palate was left denuded and was expected to heal secondarily. Though the results were promising, the techniques did not become mainstream.

Anterior maxillary distraction (AMD) is a versatile, stable, and simple technique that can be used to correct the maxillary dentoalveolar regression in the cleft maxilla after the mixed dentition phase (Video 75.1). As the osteotomy is anterior to the junction of the hard and soft palate, the velopharyngeal dimensions and soft palate activity are not affected. Thus, it is considered optimal for the correction of cleft maxillary regression in cases with preoperative moderate to severe VPI. When used in the age group of 10-16 years, there is also an associated posterior movement of the distal maxilla owing to the elasticity of the bone which may also reduce preoperative VPI to a certain extent. An added advantage is that the increased arch length can be used to accommodate un-erupted teeth and correct crowding [48-53]. 
In case postoperative VPI develops, it is advisable to wait and watch for at least 1 year prior to resorting to surgical correction. During this period, one can try conservative methods like speech therapy and bulb palatal lift prosthesis and minimally invasive methods like autologous fat injections into the soft palate and the posterior pharyngeal wall $[31,54,55]$. If the VPI does not improve to a clinically acceptable level even after a year, then surgical options need to be considered.

In terms of risk of development of postoperative obstructive sleep apnea, Furlow palatoplasty and buccal myomucosal flaps have the least adverse effect followed by sphincter pharyngoplasty and finally pharyngeal flap which has the most adverse effect $[56,57]$. Nonetheless, the pharyngeal flap is the most commonly used method, and a recent paper by Dentino et al. [58] demonstrated that the superiorly based pharyngeal flap was highly successful in correcting VPI after cleft maxillary advancement.

\subsubsection{Degree of Maxillary Hypoplasia}

The classification of cleft maxillary hypoplasia is given in Box 75.10

\section{Box 75.10: Classification of Maxillary Hypoplasia}

- Mild cases-reverse overjet below $6 \mathrm{~mm}$

- Moderate cases-reverse overjet between 6 and $10 \mathrm{~mm}$

- Severe cases - reverse jet between 11 and $16 \mathrm{~mm}$

- Extreme cases-reverse overjet equal to or greater than $17 \mathrm{~mm}$

The above classification of maxillary hypoplasia needs to be combined with the age at which the patient presents for optimal treatment planning. It should be noted that the regression is calculated only on the basis of reverse dental overjet. The presence or severity of para-nasal hollowing is not accounted for in the above classification.

\subsection{Treatment Plans}

\subsubsection{Pearls for Treatment Planning}

- If surgical treatment (distraction osteogenesis or orthognathic surgery) is performed prior to the skeletal maturity, there is a high chance of relapse due to continued skeletal growth. Thus, additional surgery will be required to correct the residual skeletal deformity. Nonetheless, distrac- tion osteogenesis is preferred over orthognathic surgery in the growing patient.

- Time constraints and patient's needs might require you to modify the ideal treatment plan. Though the overall facial profile is important, it is equally essential to establish a functional occlusion with positive overjet and good intercuspation as they go a long way in preventing relapse.

- Procedures like camouflage orthodontics, face mask protraction, and anterior maxillary distraction produce a greater change at the dentoalveolar level and fail to significantly improve para-nasal hollowing. In case of AMD, the anterior maxillary osteotomy does not extend sufficiently enough in to the posterior and superior aspect of the zygomaticomaxillary buttress region.

- Orthognathic surgery and total maxillary distraction (TMD; subtypes, internal maxillary distraction and rigid external distraction) can both correct para-nasal hollowing when combined with a modified high-level LeFort I osteotomy.

- While operating, the facial profile and occlusion can be immediately appreciated during orthognathic surgery. Results can similarly be approximated in total maxillary distraction (TMD) by activating the distractor to the desired extent on the operating table. This is possible as the posterior extent of a conventional LeFort I osteotomy lies in the region of the more mobile soft palate.

- While performing anterior maxillary distraction, the final facial profile and occlusion cannot be immediately appreciated on the OT table as the posterior extent of the maxillary osteotomy lies anterior to the permanent first molar. The palatal mucosa in this region is firmly attached to the underlying bone, and excessive activation of the distractor can lead to stripping of the mucosa from the underlying bone.

- Masticatory efficiency is not significantly compromised during AMD, as the device is fairly rigid and the posterior limit of the osteotomy is anterior to the permanent first molars. A complete LeFort I osteotomy, like that used in total maxillary distraction (TMD), reduces masticatory efficiency on account of increased mobility of the whole maxilla on the application of masticatory loads.

- One needs to take into account that a reverse overjet of " $x \mathrm{~mm}$ " requires a net advancement of " $x+2 \mathrm{~mm}$ " to obtain adequate overjet and overbite. Hence, a reverse overjet of $8 \mathrm{~mm}$ requires a net advancement of $10 \mathrm{~mm}$ for adequate correction. If one wants to accommodate for expected relapse, then one needs to overcorrect by at least $20 \%$. Hence, the actual amount of advancement required would be $10+2$, i.e., $12 \mathrm{~mm}$.

- Limits of movements with orthognathic surgery: Conventional orthognathic surgical advancement of the maxilla beyond $10 \mathrm{~mm}$ increases the risk of relapse on account of the scar tissue in the soft palate and upper lip 
regions. As the mandible is usually unaffected in cleft maxillary hypoplasia, a setback beyond $8 \mathrm{~mm}$ leads to a poor aesthetic result and is also associated with higher relapse rates.

- A reverse overjet of $16 \mathrm{~mm}$ in cleft maxillary hypoplasia requires a net advancement of $18 \mathrm{~mm}$. The maxilla can be advanced by $10 \mathrm{~mm}$, and the mandible can be setback by $8 \mathrm{~mm}$ to achieve the desired correction. Thus, a reverse overjet of $16 \mathrm{~mm}$ can be treated by orthognathic surgery with acceptable stability in the long term. Although it is possible to treat a reverse overjet greater than $16 \mathrm{~mm}$ with orthognathic surgery, it is associated with a higher relapse rate.

- When the cleft maxilla is advanced $>10 \mathrm{~mm}$, there is an increased risk of damage to the palatal vascular pedicle on account of the inability of the scarred soft palate to stretch and accommodate the change [59]. Furthermore, there is also risk of suture site dehiscence in the maxillary labial vestibule as this region would be closed under tension on account of the presence of scarred tissue with minimal elasticity $[37,60]$.

- Distraction osteogenesis (AMD/TMD) can be used for all spans of maxillary advancement and is preferred for advancements $>10 \mathrm{~mm}$ on account of the stability of results in the long term [61, 62]. There is also minimal risk of damage to the palatal vascular pedicle as the advancement is gradual and a certain degree of histogenesis accompanies the distraction osteogenesis.
- The span of movement (small or large) or mode of advancement (total maxillary distraction or orthognathic surgery) is not to be associated with an increased risk for deterioration of preoperative VPI.

- Determining preoperative speech and VPI status is a must: perceptual speech assessment, acoustic measurement with nasometer, video nasoendoscopy (or video fluoroscopy), and lateral cephalometric analysis.

- If there is no preoperative VPI, then there is minimal risk for worsening of speech and occurrence of VPI postoperatively.

- If there is borderline (or greater) VPI preoperatively, then there is a high risk for worsening of VPI postoperatively.

- Wait for at least 1 year before considering surgical correction of postoperative VPI.

\subsubsection{Age Group of 6-11 Years (Fig. 75.1)}

The patient has a mixed dentition during this phase. There are multiple un-erupted dental follicles present that can pose a problem to certain surgical procedures. Alveolar bone grafting is preferably performed during this phase as it is associated with higher success rates [26]. Large oronasal fistulae, if present, need to be closed prior to secondary alveolar bone grafting.

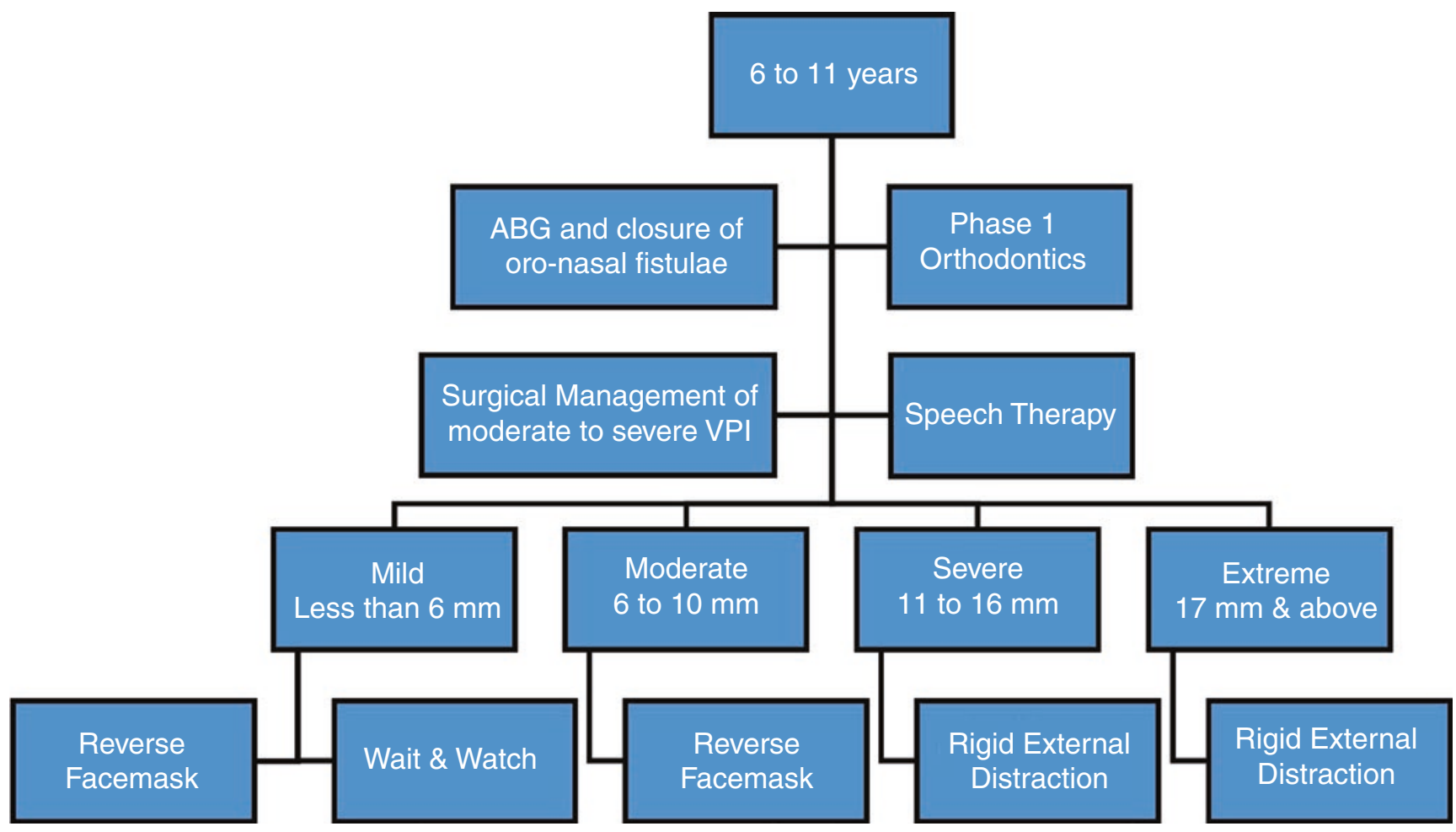

CAssociation of Oral and Maxillofacial Surgeons of India

Fig. 75.1 Treatment plan for age group 6-11 years 
If the child presents with a mild regression, one can choose to wait and watch or proceed with dentofacial orthopedics using a reverse pull headgear to achieve protraction of the maxilla. If the child presents with moderate regression, then one must proceed with reverse pull headgear therapy to achieve some degree of correction.

The usage of reverse facemask therapy requires considerable patient co-operation and works by stimulating growth at the various maxillary suture sites (Fig. 75.2a-c). It is usually combined with a maxillary expansion appliance that helps disrupt the circum-maxillary sutural system and increase the effects of the orthopedic face mask. The general effect produced is that of a downward and forward movement of the maxilla, backward rotation of the mandible, and a net increase in the lower facial height. However, the response varies widely from individual to individual, and long-term stability is also questionable [7, 63-66].

The stability and extent of correction with reverse facemask therapy reduces with increasing severity of labiopalatal clefting and absence (or failure) of prior alveolar bone grafting [63-66]. The degree of ossification of the zygomaticomaxillary buttress also plays an important role in the results of facial protraction therapy. Earlier stages (younger age group) of ossification are associated with a greater span of movement and skeletal and dental changes. Later stages of ossification (older age group) are associated with a smaller span of movement and mainly dentoalveolar changes [67, 68]. Today, skeletal anchorage is slowly replacing traditional tooth borne anchorage on account of better control of degree of rotation of the mandible and greater potential for skeletal movements [69, 70]. In patients who are less co-operative, one can consider using a modified technique with inter-maxillary elastics between a miniplate secured to the zygomaticomaxillary buttress region posteriorly and another miniplate secured to the mandible anteriorly (Bone-anchored maxillary protraction - BAMP). This technique has provided promising results which are comparable to traditional reverse facemask therapy. However, this modification can be performed only after the eruption of the mandibular canine to allow for plating in the anterior mandible $[69,71,72]$.

Very rarely will a child present with severe or extreme regression in this age group. Rigid external distraction (RED) is the only option available for the correction of such a severe discrepancy and is mainly used in syndromic patients presenting with moderate to severe obstructive sleep apnea and in patients with a poor psychological status. RED allows for high osteotomies as it does not rely on rigid fixation techniques to secure the distractor. This helps avoid injury to tooth follicles in the growing patient while simultaneously correcting para-nasal hollowing. On the contrary, internal total maxillary distraction (ITMD) and anterior maxillary distraction (AMD) cannot be used as the lower-level osteotomies used in these procedures will damage the un-erupted dental follicles. The plates of the internal distractor also need to be secured to the bone with screws, which will also cause damage to the tooth follicles.

In spite of the above treatments, it is difficult to maintain results in the long term on account of continued mandibular growth. Thus, surgery will mostly be required once the patient reaches skeletal maturity to correct any residual skeletal deformity. However, the final amount of maxillary advancement will be much lesser resulting in increased postoperative stability of the cleft maxilla.

\subsubsection{Age 12-16 Years (Fig. 75.3)}

All permanent teeth (except the third molars) have erupted. The absence of un-erupted dental follicles makes procedures like AMD and ITMD (internal total maxillary distraction) feasible in this age group. Due to deficient arch length, there may be moderate to severe crowding. Some permanent teeth may have remained un-erupted, impacted, or erupted ectopically adding to the complexity of the treatment. If alveolar bone grafting has not been done prior or has failed, it needs to be performed during this phase. Large oronasal fistulae, if present, also need to be closed in preparation for orthognathic surgery.

If the regression is mild to moderate, one can consider camouflage orthodontics, maxillary protraction therapy, or AMD in order to create an acceptable occlusion. Alternatively, we can choose to wait and watch and directly correct the maxillary hypoplasia once growth is complete (Fig. 75.4a, b).

Severe to extreme maxillary regression is preferably treated with AMD. The available span of most commercially available hyrax screws does not exceed $13 \mathrm{~mm}$. Thus, there are two options available to the clinician: repeat the AMD twice in a single stage or in a two-staged manner (at least 1 year apart) [50]. The author prefers to repeat the AMD activation twice, in a single stage. This requires the fabrication and immediate application of a fresh appliance, once the first appliance has attained complete activation of the incorporated Hyrax screw. Great care should be taken to avoid excessive pressure on the anterior maxilla while fitting the new appliance as the callus is not fully mature and large forces may easily destroy it. Alternatively, we can consider total maxillary distraction (ITMD or RED) (Figs. 75.5a-d and 75.6a-f) as long as the patient does not have moderate to severe preoperative VPI (Also see Fig. 70.17).

In spite of the above treatments, it is difficult to maintain results in the long term on account of continued mandibular growth. Thus, surgery will mostly be required once the patient reaches skeletal maturity to correct any residual skel- 

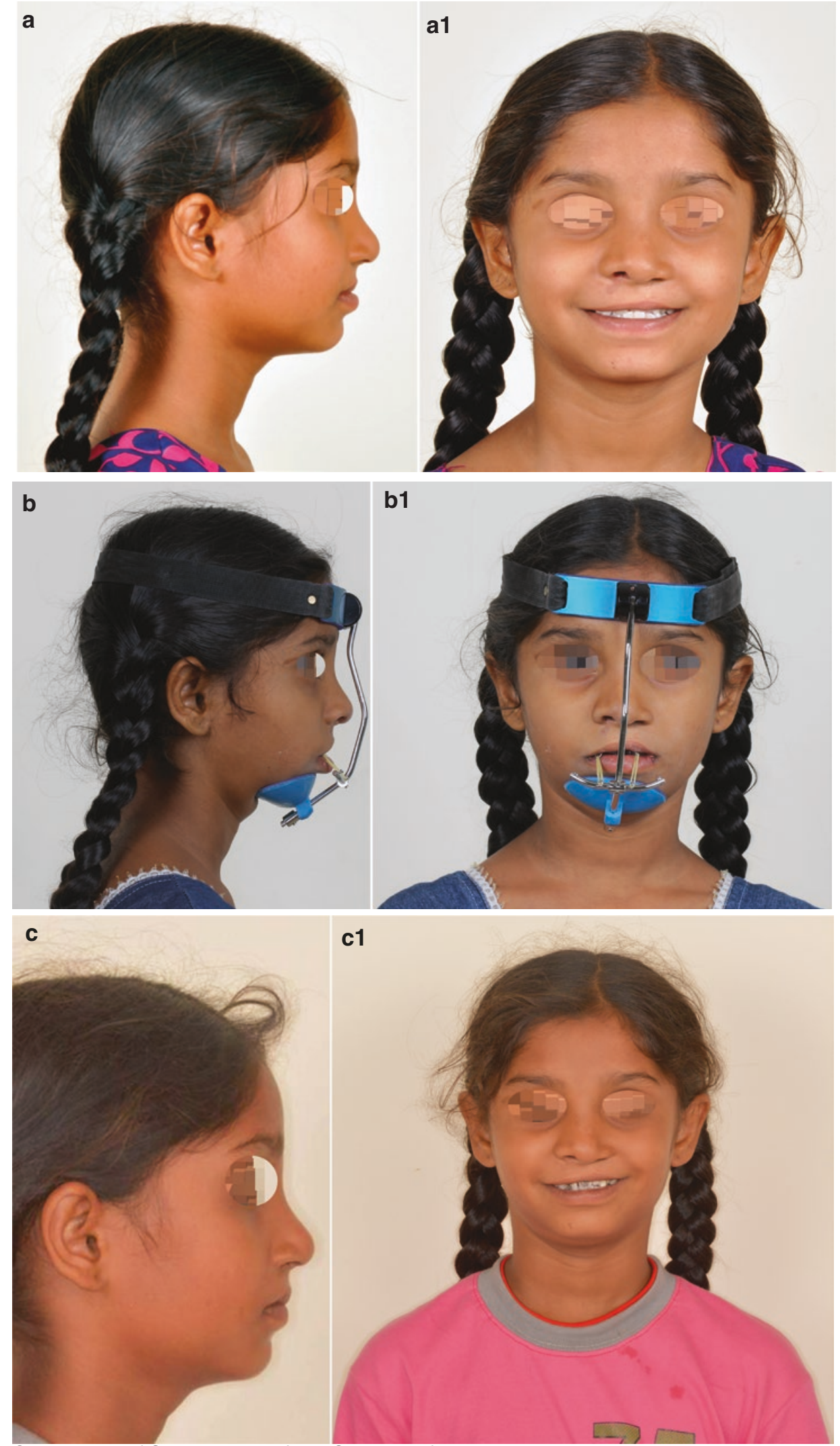

CAssociation of Oral and Maxillofacial Surgeons of India

Fig. 75.2 (a-c) Reverse pull headgear therapy in a growing child with cleft maxillary hypoplasia. (a, a1) Pre-treatment profile and frontal photographs, (b, b1) Profile and frontal photographs of patient after application of "reverse-pull headgear", (c, c1) Post-treatment profile and frontal photographs demosntrating an improvement in the patient's profile 


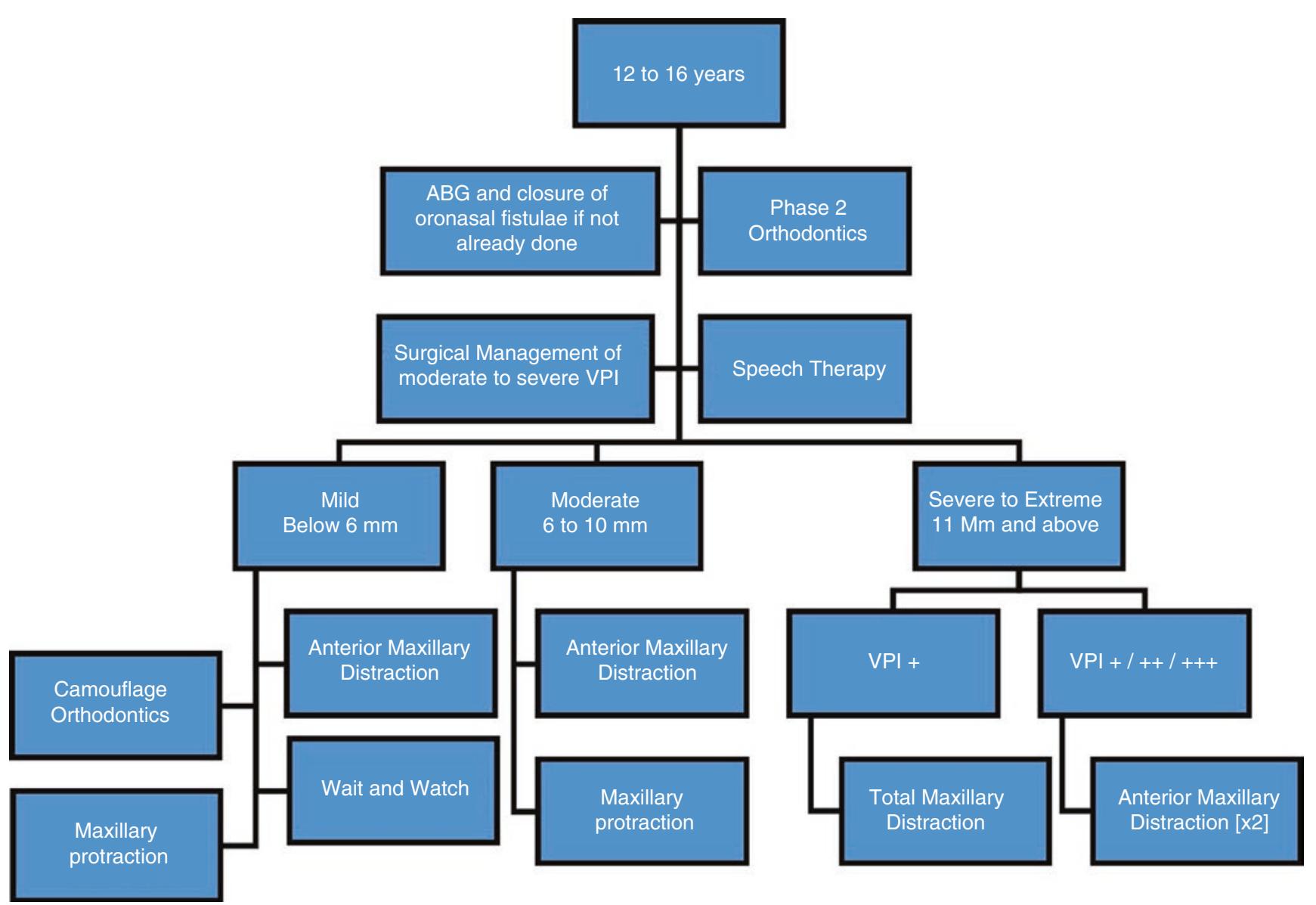

CAssociation of Oral and Maxillofacial Surgeons of India

Fig. 75.3 Treatment plan for age group 12-16 years

\section{SEVERE - 11 TO $16 \mathrm{~mm}$}

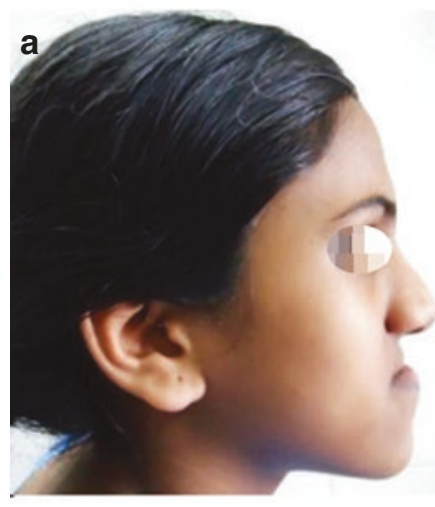

PRE-AMD

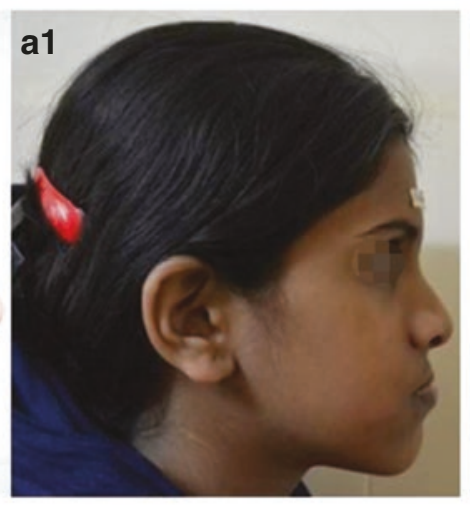

POST-AMD

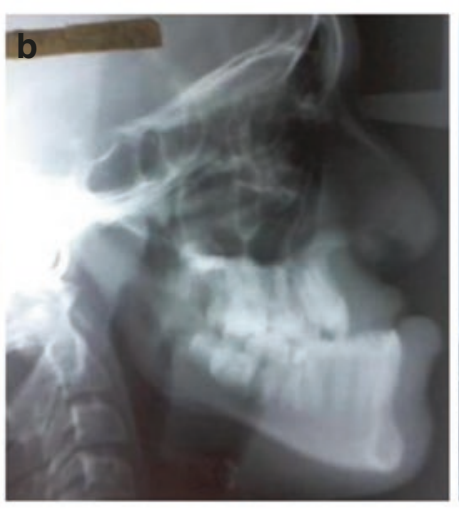

PRE-AMD

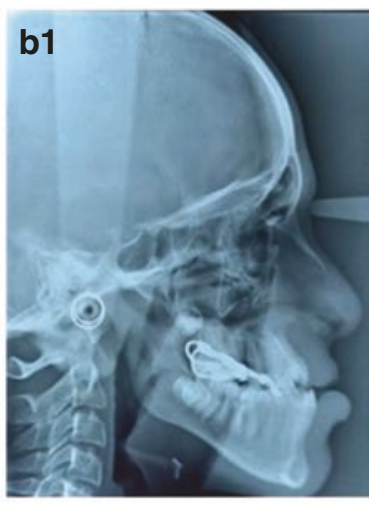

POST-AMD

(C)Association of Oral and Maxillofacial Surgeons of India

Fig. 75.4 (a, b) Severe reverse overjet at 14 years of age and mild VPI. Anterior maxillary distraction was performed (AMD). Final correction with orthognathic surgery to be done after 16 years of age 

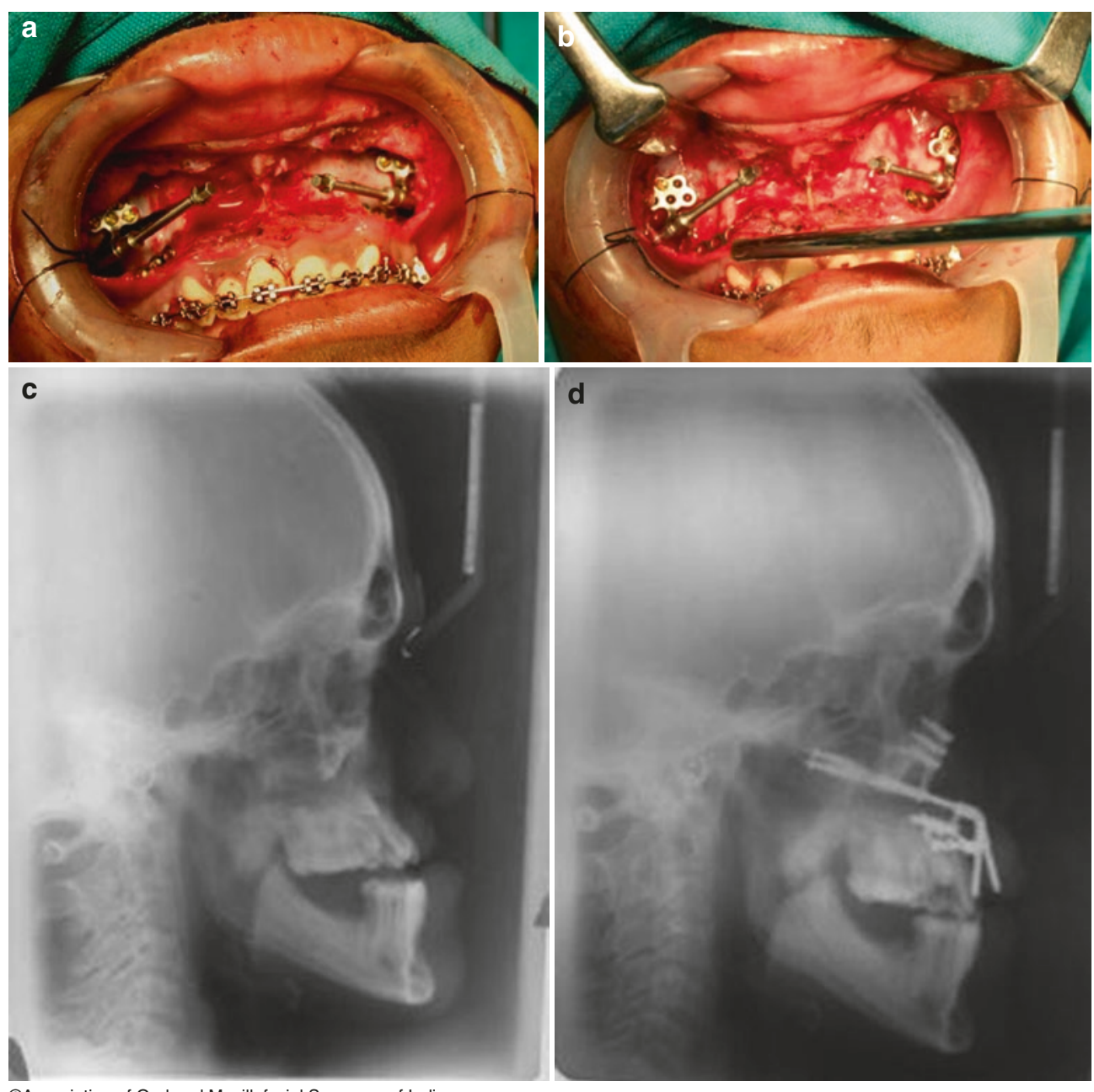

Fig. 75.5 (a-d) Use of internal maxillary distraction in the management of CMH. (a) Intra-operative positioning of internal maxillary ditractors, (b) post-distraction picture prior to the removal of distractor

devices, (c) Pre-operative lateral cephalogram and (d) Post-operative lateral cephalogram demonstrating ditractor in-situ

etal deformity. However, the final amount of maxillary advancement will be much lesser resulting in increased postoperative stability of the cleft maxilla.

\subsubsection{Age 17 Years and Above (Fig. 75.7)}

If prior alveolar bone grafting has failed or has not been performed, a decision should be made as to whether it needs to be performed or not. Large oronasal fistulae, if present, need to be closed in preparation for orthognathic surgery.

If the regression is mild to moderate and VPI is absent or negligible, then either total maxillary distraction, AMD, or orthognathic surgery can be performed. Orthognathic surgery

is preferred in this scenario as we can achieve immediate improvement in facial profile and occlusion (Figs. 75.8a-h, 75.9a-h). If there is moderate to severe VPI preoperatively, then it is advisable to perform AMD to avoid further deterioration of the same.

If the regression is severe to extreme and the VPI is absent or negligible, then either orthognathic surgery (Fig. 75.10a-f), AMD, or TMD can be performed. AMD may have to be repeated twice in the same sitting or in a stage manner as described previously. If optimal esthetics is the goal, then AMD followed by conventional LeFort I maxillary advancement is the ideal treatment plan (Fig. 75.11a-g). The only drawback of this procedure is the prolonged treatment duration as a minimum waiting period 


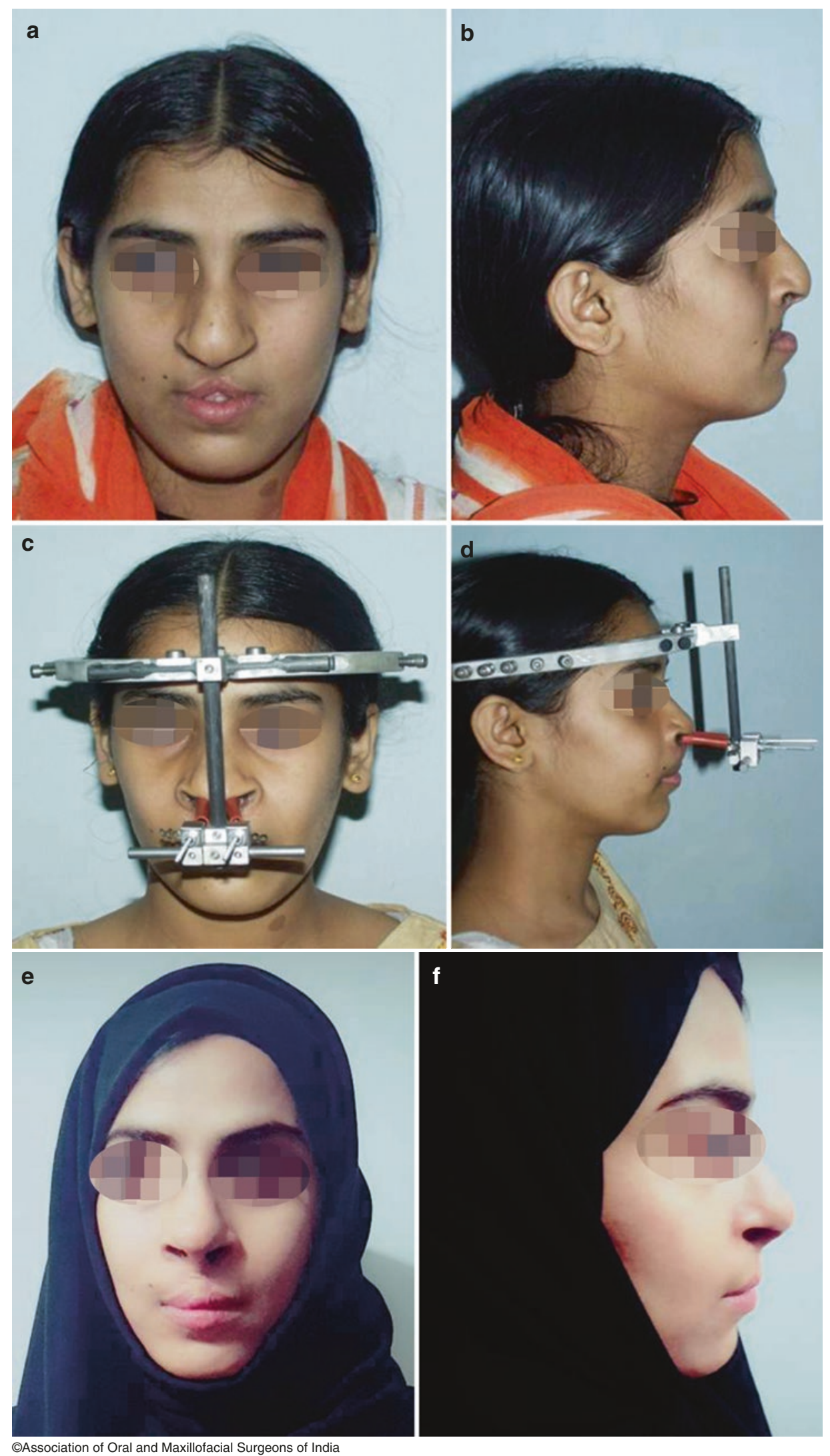

Fig. 75.6 (a-f) Patient treated with rigid external distractor (RED). (a, b) Pre-operative frontal and profile photographs, demonstating hypoplastic midface and concave profile. (c, d) Frontal and profile pho- tographs showing RED in situ. (e, f) Post-operative frontal and profile photographs demonstrating good midface fullness and a convex facial profile 


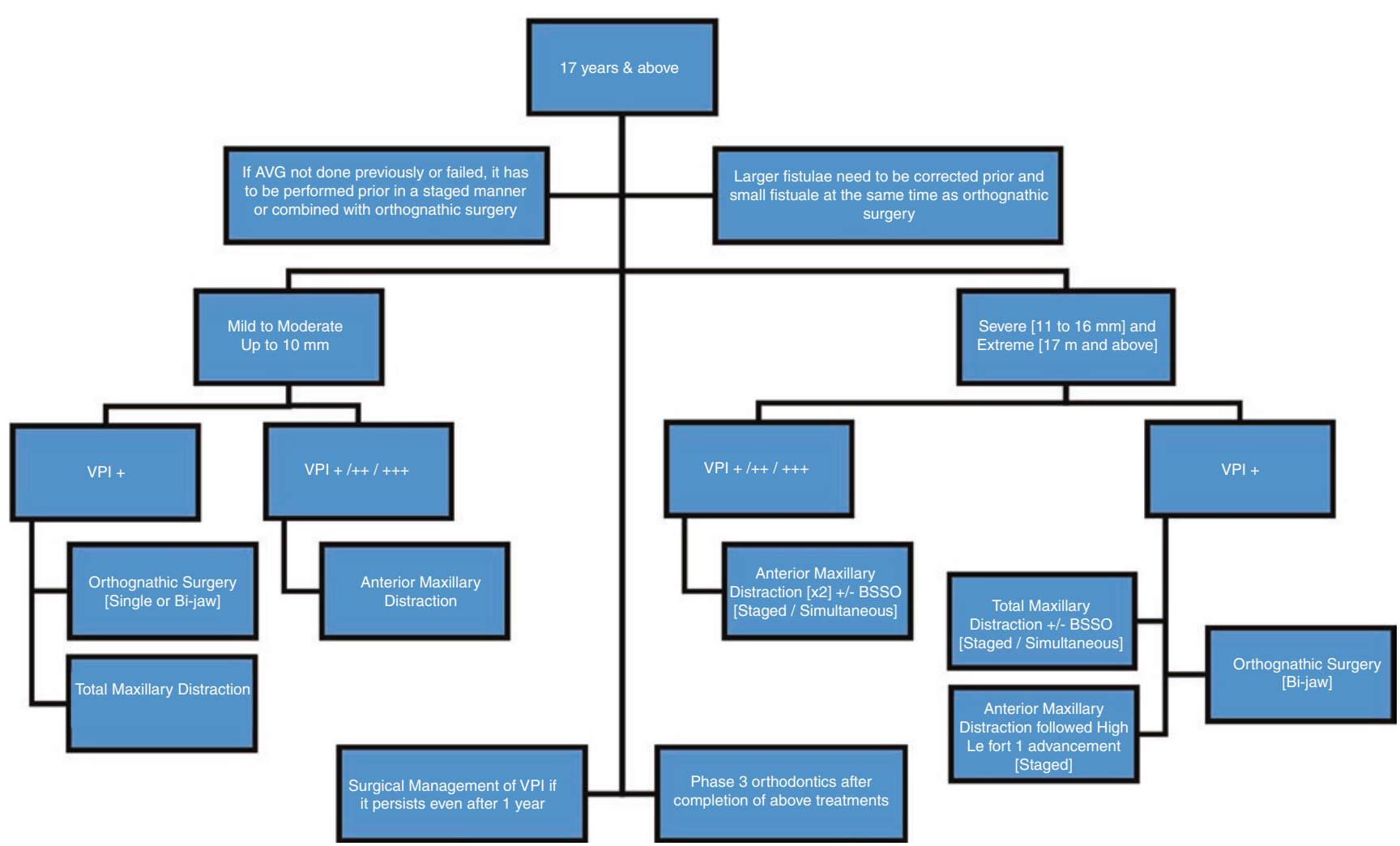

(C)Association of Oral and Maxillofacial Surgeons of India

Fig. 75.7 Treatment plan for age group 17 years and above

of 1 year is needed between both surgeries. If there is moderate to severe VPI preoperatively, then it is advisable to perform AMD to avoid further deterioration of the same. As a means of saving time or if the mandible is truly prognathic, AMD and TMD can be combined with a mandibular setback (using bilateral sagittal split osteotomy) in a simultaneous or staged manner to reduce the span needed to be distracted [73].

\subsection{LeFort I Procedure for Cleft Maxillary Hypoplasia}

The protocol preferred by the authors is described below.

\subsubsection{Preoperative Investigations}

The preoperative investigations are described in Box 75.11 .

Chronic Maxillary Sinusitis Most CLP patients suffer from chronic maxillary sinusitis on account of the presence of nasal obstructions and residual oronasal fistulae. It is the author's opinion that such patients need to be referred to an ENT specialist at least 3 months prior as active sinusitis affects the quality of the bone in the maxilla.

\section{Box 75.11: Preoperative Investigations}

Primary Investigations

Clinical diagnosis, pre-anesthetic assessment (blood investigations, chest x-ray, ECG, additional investigations for any significant medical history), facial photographs, cephalometric analysis (lateral cephalogram and postero-anterior cephalogram), articulated study models with bite registration and facebow transfer, dental model analysis, orthopantomogram, perceptual speech assessment, video nasoendoscopy (or video fluoroscopy) for velopharyngeal insufficiency, psychological screening, and patient education regarding realistic expectations

Adjunctive Investigations

3D computed tomography scans, stereolithographic model, sleep studies, and 3D virtual surgical planning 


\section{Mild - Below $6 \mathrm{~mm}$}
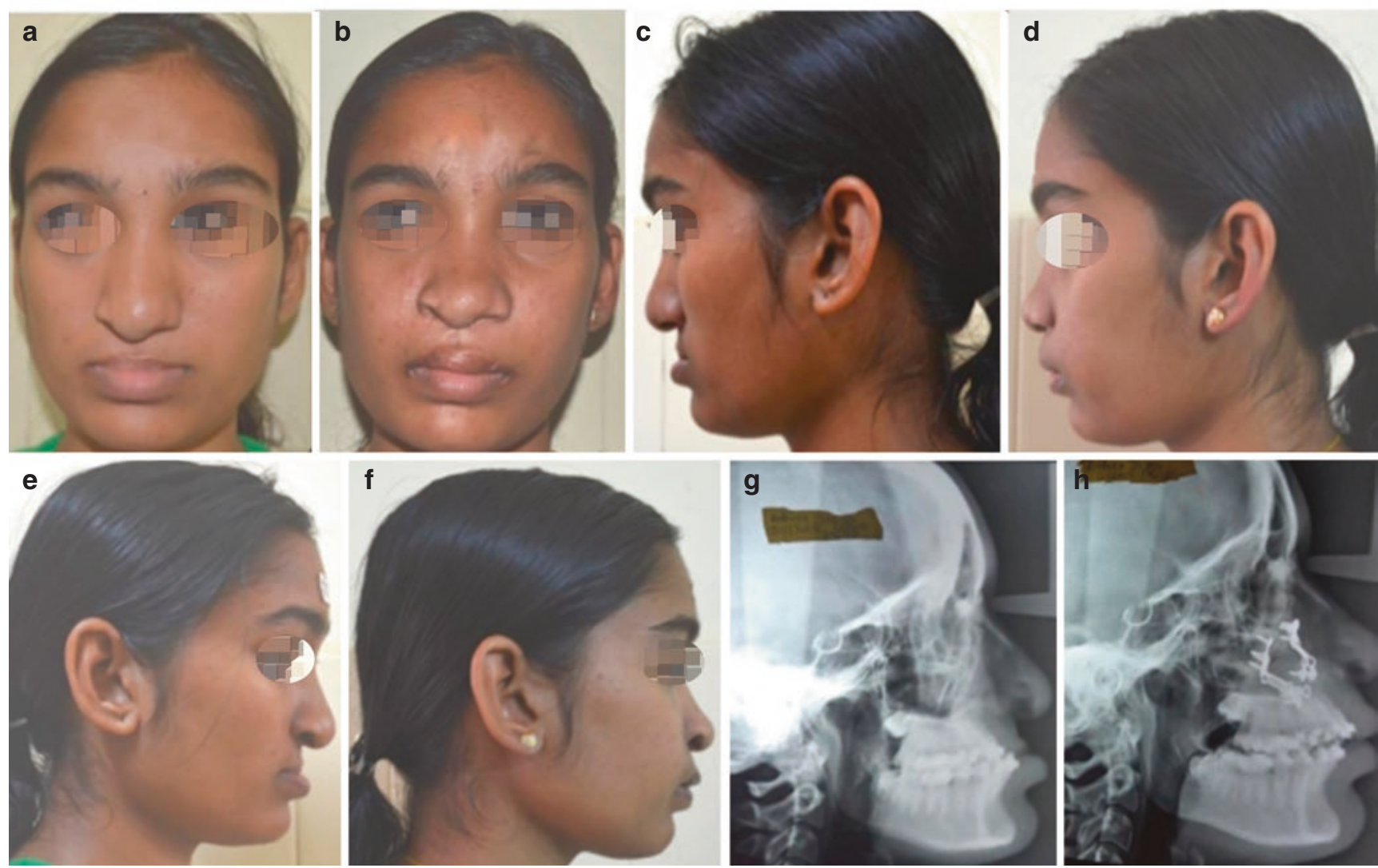

CAssociation of Oral and Maxillofacial Surgeons of India

Fig. 75.8 (a-h) Mild reverse overjet and no preoperative VPI. The patient was treated with single jaw orthognathic surgery (maxillary advancement). (a, b) Pre and post-operative frontal photographs. (c, d)
Pre and post operative profile photographs (left side). (e, f) Pre and post-operative profile photographs (right side). (g, h) Pre and post-operative lateral cephalograms

\subsubsection{Preoperative Preparation}

A single dose of $8 \mathrm{mg}$ dexamethasone (half-life of 36-54 h) is given preoperatively to help reduce postsurgical airway and maxillofacial edema. It also has a synergistic analgesic effect when combined with postoperative analgesics. As a only a single dose is given, it is associated with minimum side effects [74, 75]. A single dose of $1 \mathrm{gm}$ tranexamic acid is given $1 \mathrm{~h}$ preoperatively as it helps reduce intraoperative blood loss [76].

\subsubsection{Intubation}

Nasal intubation is preferred followed by submental intubation. In case a pharyngeal flap or nasal obstruction (enlarged inferior turbinates or deviated nasal septum) is present, it is advisable to perform fiber-optic assisted awake intubation.
Alternatively, it may be necessary to pass a more rigid tube or catheter initially after which the endotracheal tube is passed over it.

The author always prefers to use a flexometallic nasoendotracheal tube as the tube is able to maintain its integrity even if damaged during the LeFort I osteotomy on account of the additional strength imparted by the metal coils.

\subsubsection{General Anesthesia}

The author commonly uses hypotensive anesthesia during orthognathic surgery as it provides a clean hemostatic field, reduces blood loss, and shortens hospital stay. There is an association between hypotensive anesthesia, forces generated during pterygomaxillary dysjunction, and optic nerve damage. Risk for optic nerve damage increases when hypotensive anesthesia is used in head and neck surgery which is 


\section{MODERATE - 6 to $10 \mathrm{~mm}$}

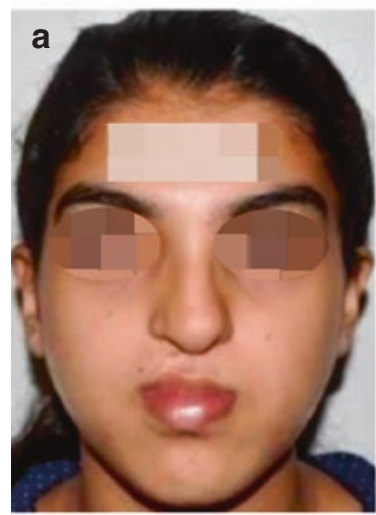

e
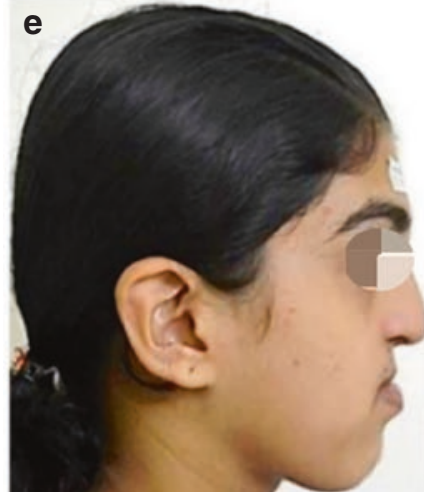

CAssociation of Oral and Maxillofacial Surgeons of India

Fig. $75.9(\mathbf{a}-\mathbf{h})$ - Moderate reverse overjet and mild preoperative VPI. The patient was treated with orthognathic surgery alone (maxillary advancement and advancement genioplasty). (a, b) Pre and post-opera-
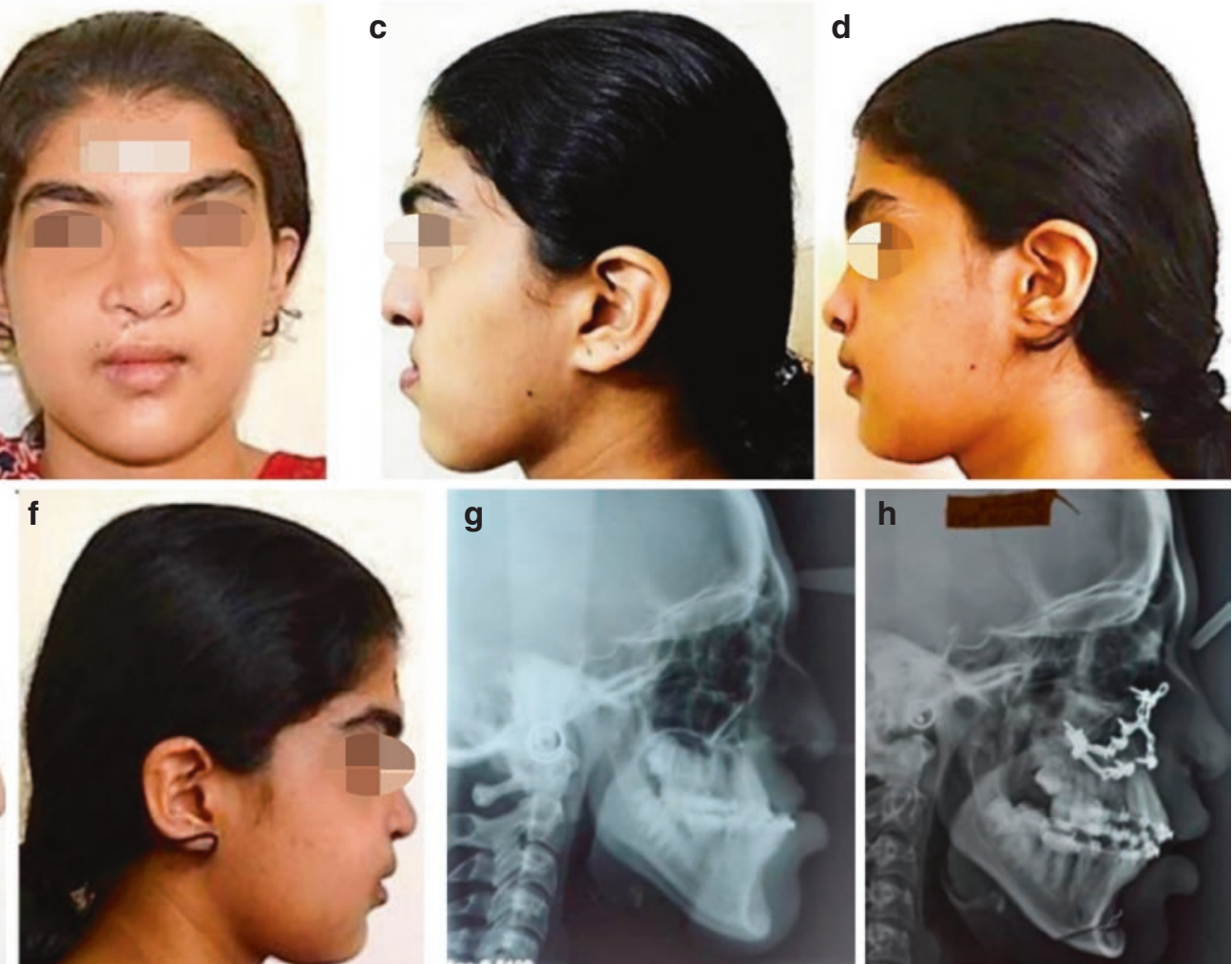

tive frontal photographs. (c, d) Pre and post operative profile photographs (left side) (e, f) Pre and post-operative profile photographs (right side). (g, h) Pre and post-operative lateral cephalograms

prolonged ( $>6 \mathrm{~h})$ and large amount of blood loss $(>11)$ has taken place [77-82].

A larger amount of force is needed for pterygomaxillary dysjunction in CLP patients on account of the thicker pterygomaxillary junction. The stray forces, generated as a result of the dysjunction, can dissipate toward the orbital cavity and optic foramen with a magnitude potent enough to cause damage to the optic nerve. This is possible due to the orbital extensions of the palatine and sphenoid bones [7, 83, 84]. Thus, the author prefers to maintain hypotensive anesthesia during the entire orthognathic surgery except during pterygomaxillary dysjunction.

\subsubsection{Cleft LeFort I Osteotomy (Video 75.2)}

In cases of unilateral CLP, a routine incision in the height of the maxillary vestibule is used, and care should be taken that it extends only to the mesial surface of the first maxillary

molars on both sides [7, 30, 85] (Refer Chap. 69 on Maxillary orthognathic procedures).

In cases of bilateral CLP, the incision is modified such that it extends from the lateral incisor to mesial surface of the first molar on both sides. A vertical stab incision is made in the midline to allow for placement of the nasal septal osteotome. This is to preserve blood supply to the pre-maxillary segment as most of its blood supply comes from the upper lip $[2,7,28,30]$.

Frequent surgery in the cleft maxilla leads to creation of scar tissue in the buccal, palatal, and upper lip regions. This scar tissue has compromised vascularity and healing ability. Therefore, it is essential to maintain an adequate soft tissue pedicle. There have also been suggestions to use modified vertical incisions instead of circumvestibular incisions, but it increases the difficulty of the procedure manyfold due to poor access and visualization $[2,3,86]$. Careful and gentle retraction of tissues (especially the pedicles) is essential throughout the procedure and especially during the down-fracture process. 


\section{SEVERE - 11 to $16 \mathrm{~mm}$}

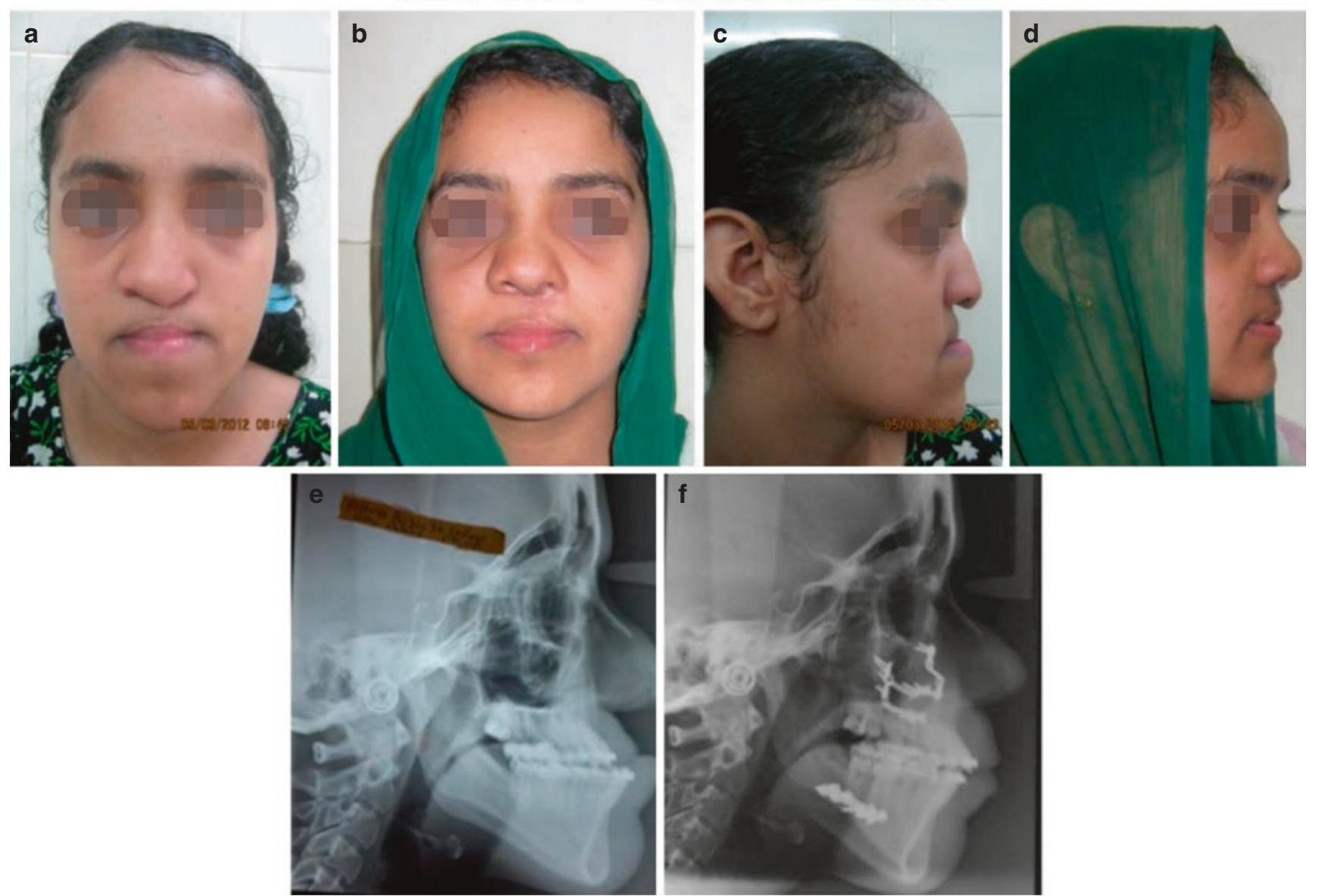

CAssociation of Oral and Maxillofacial Surgeons of India

Fig. 75.10 (a-f) Severe reverse overjet and mild preoperative VPI. The patient was treated with bi-jaw orthognathic surgery. (a, b) Pre and post operative frontal photographs. (c, d) Pre and post operative profile photographs. (e, f) Pre and post operative lateral cephalograms

The nasal mucosa is routinely elevated from the walls and floor of the nasal cavity prior to starting the LeFort I osteotomy. In the cleft maxilla, there is no intervening bone between the oral and nasal cavity in the region of the cleft; instead, the nasal mucosa is fused to the palatal mucosa due to the previously performed palatoplasty. This tissue should be sharply dissected close to the nasal floor, and care should be taken to avoid perforating the palatal mucosa. This step also aids in the down-fracture and mobilization of the maxilla.

The cleft maxilla usually exhibits para-nasal hollowing. Hence, the routine LeFort I osteotomy may not suffice for complete correction of cleft maxillary hypoplasia. Instead a high LeFort I osteotomy is used which has the added advantage of correcting the para-nasal hollowing as well [7, 30, 86]. Care should be taken to avoid damage to the tooth roots and the infra-orbital nerve as it exits from the infra-orbital foramen (Fig. 75.12). One should keep in mind that the descending palatine artery is closer to the lateral pyriform rim while performing the lateral nasal wall osteotomy.

To completely mobilize the maxilla during a LeFort I osteotomy, it is necessary to perform a pterygomaxillary dysjunction which separates the maxilla from the pterygoid plates. The maneuver is essentially blind and involves orienting a pterygoid chisel (curved osteotome) in a downward, medial, and anterior direction such that it engages the lower part of the pterygomaxillary fissure while maintaining a safe distance from the internal maxillary artery [87-89].

Studies have revealed that the medial pterygoid plate is shorter and the pterygomaxillary junction is thicker in cleft patients as the region around the hamular notch is fre- 


\section{EXTREME - Equal to or Greater than $17 \mathrm{~mm}$}

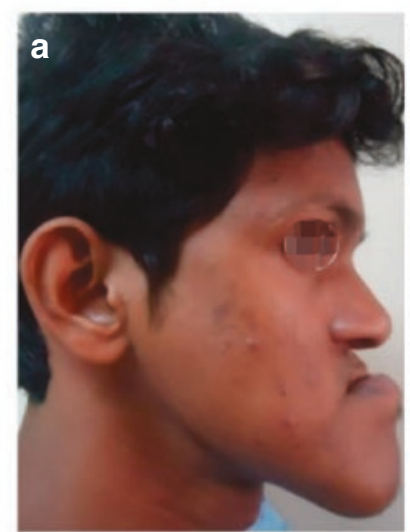

PRE-OP

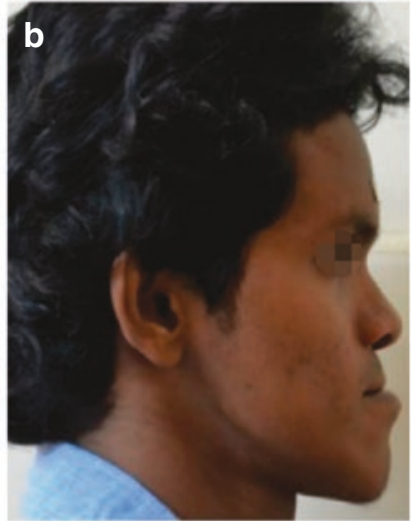

$1^{\text {st: }}$ POST-AMD
17 years

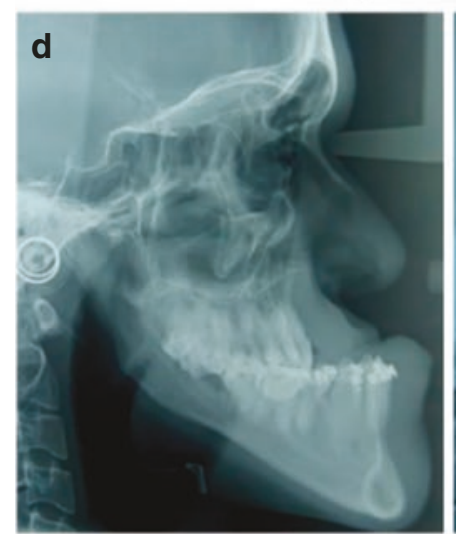

PRE-AMD

17 years
18 years

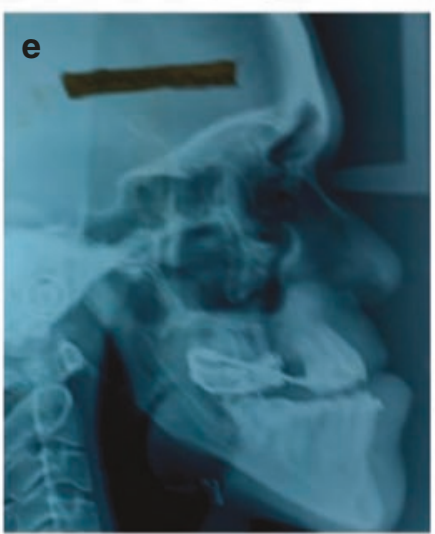

POST-AMD

17 years

@Association of Oral and Maxillofacial Surgeons of India

Fig. 75.11 (a-g) Extreme reverse overjet and mild preoperative VPI. 1st stage corrected by anterior maxillary distraction (AMD). Note the persistent para-nasal hollowing that is only partially corrected by AMD. 2nd stage completed by bi-jaw orthognathic surgery (OGS) with improvement in para-nasal hollowing. (a) Pre-operative profile photo-

quently manipulated during palatoplasty. The shorter medial pterygoid plate, by virtue of its smaller dimensions, may be more prone to fracture which increases the risk for vascular complications [87, 88]. Furthermore, the thicker pterygomaxillary junction requires a larger magnitude of force to achieve adequate separation. The usage of greater force leads to less control over this blind manoeuvre, thus increasing the risk for vascular complications (internal maxillary artery damage, carotid cavernous sinus) and neurologic (optic nerve damage) and skull base fractures (sphenoid fractures) [84].

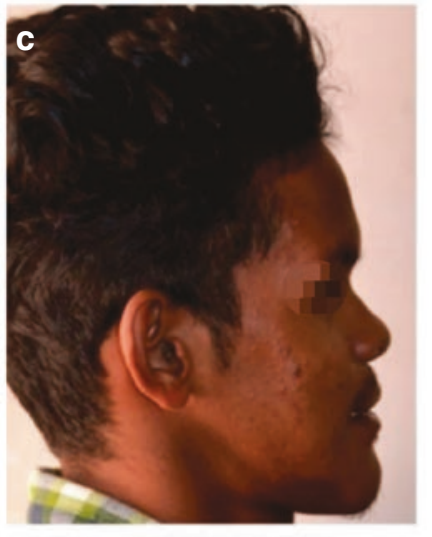

$2^{\text {nd }}$ : POST-OGS

20 years

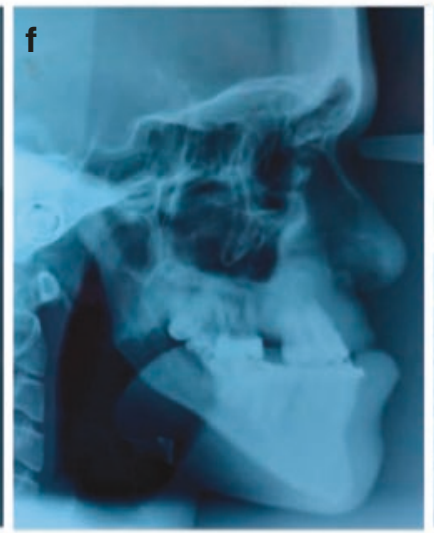

CONSOLIDATION 18 years

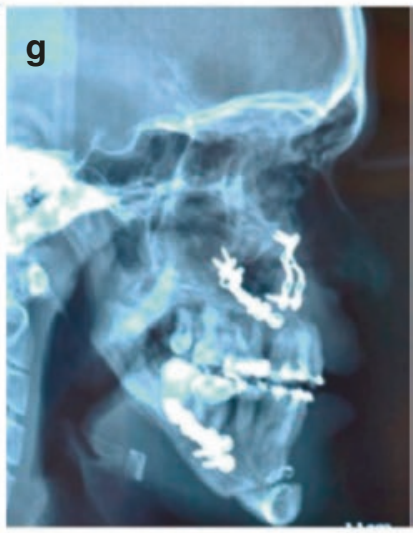

POST-OGS 20 years graph. (b) Profile after stage 1 correction wthe AMD. (c) Profile after stage 2 correction with orthognathic surgery. (d) Pre-operative lateral cephalogram. (e) Lateral cephalogram after stage 1 - AMD. (f) Postconsolidation lateral cephalogram. (g) Lateral cephalogram after stage 2 -orthognathic surgery

There have been many modifications suggested to the original technique with an intention to reduce complications [87, 88, 90-95]. However, their use has never been documented widely in CLP cases. One may also attempt to use a piezo-surgical instrument or sequentially increase the size of the osteotomes to help reduce the force required for final pterygomaxillary separation [96, 97]. Another important consideration would be the preference of a third molar vertical osteotomy cut instead of a pterygomaxillary disjunction. This manoeuvre is anatomically less hazardous, allows greater mobility of the segments, allows a larger vascular 
pedicle to be maintained and permits the use of interpositional bone graft in the osteotomised area, after the advancement in order to prevent relapse.

Once pterygomaxillary dysjunction has been performed, the maxilla is down-fractured using leverage or specialized instruments like the Smith's spreader. If the

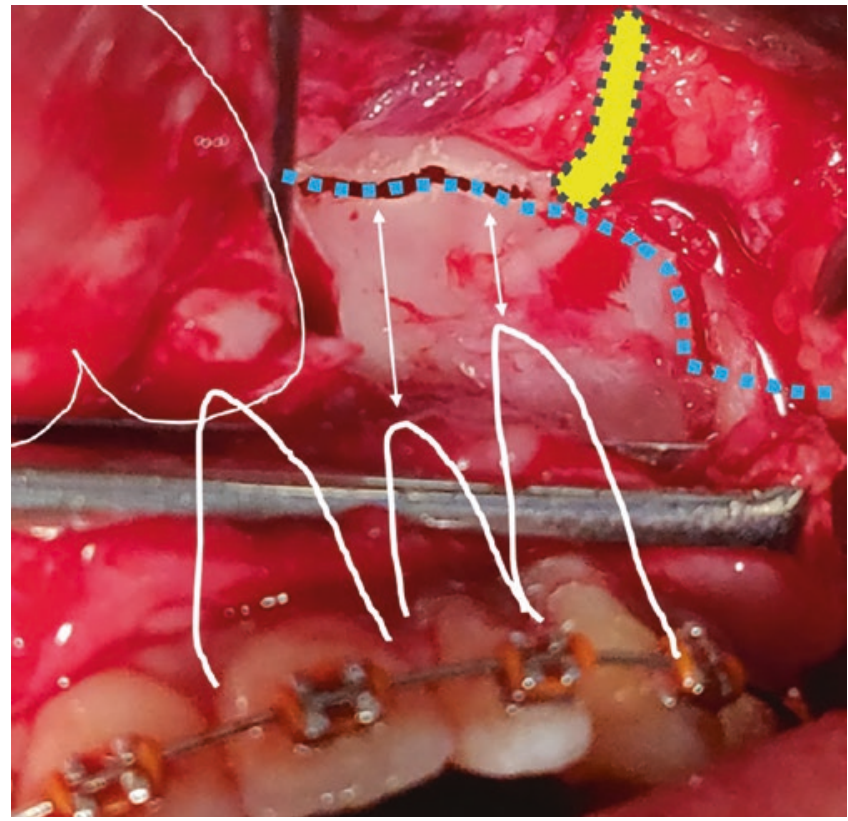

CAssociation of Oral and Maxillofacial Surgeons of India

Fig. 75.12 Modified high LeFort I osteotomy (blue) cut to help correct para-nasal hollowing. Avoid damage to the infra-orbital nerve (yellow) and roots of teeth (white) while making the osteotomy. The pyrifiorm rim is marked in orange nasal mucosa has not been dissected from the palatal mucosa previously, then it has to be done at this point $[2$, $7,30]$. After the down-fracture, it is important to suture the divided edges of the nasal mucosa to regain continuity of nasal lining. In the author's opinion, the edges of the divided nasal mucosa are a common source of bleeding postoperatively if left un-sutured (Fig. 75.13a, b). The presence of nasal obstructions like enlarged inferior turbinates can be corrected at this time.

After the down-fracture, the process of mobilizing the maxilla is done in a gradual progressive manner as the scarred tissues are less compliant. Specialized instruments like the Tessier's mobilizer can be used. If a pharyngeal flap is present and is impeding maxillary advancement, it may need to be incised. The maxilla is finally advanced to its desired position and should be seated in a passive manner. Signs of resistance at this point may indicate that the maxilla has not been adequately mobilized, and the previous steps need to be revisited. If resistance to the desired maxillary position persists, then one must consider to switch to maxillary distraction or setback the mandible to avoid postoperative relapse. In situations where an alveolar bone grafting procedure has not been performed, or where the take of the grafting is sub-optimal, the cleft maxilla may present as a two-piece (unilateral cleft) or a three-piece (bilateral) maxilla. This may necessitate the use of transverse maxillary plating (Fig. 75.14a, b), for stabilization of the segmented bone.

There may also be need for segmental osteotomies as it is difficult to completely co-ordinate both arches with presurgical orthodontics on account of the variable anatomy of the cleft maxilla. The cleft alveolar gap can be opened or closed
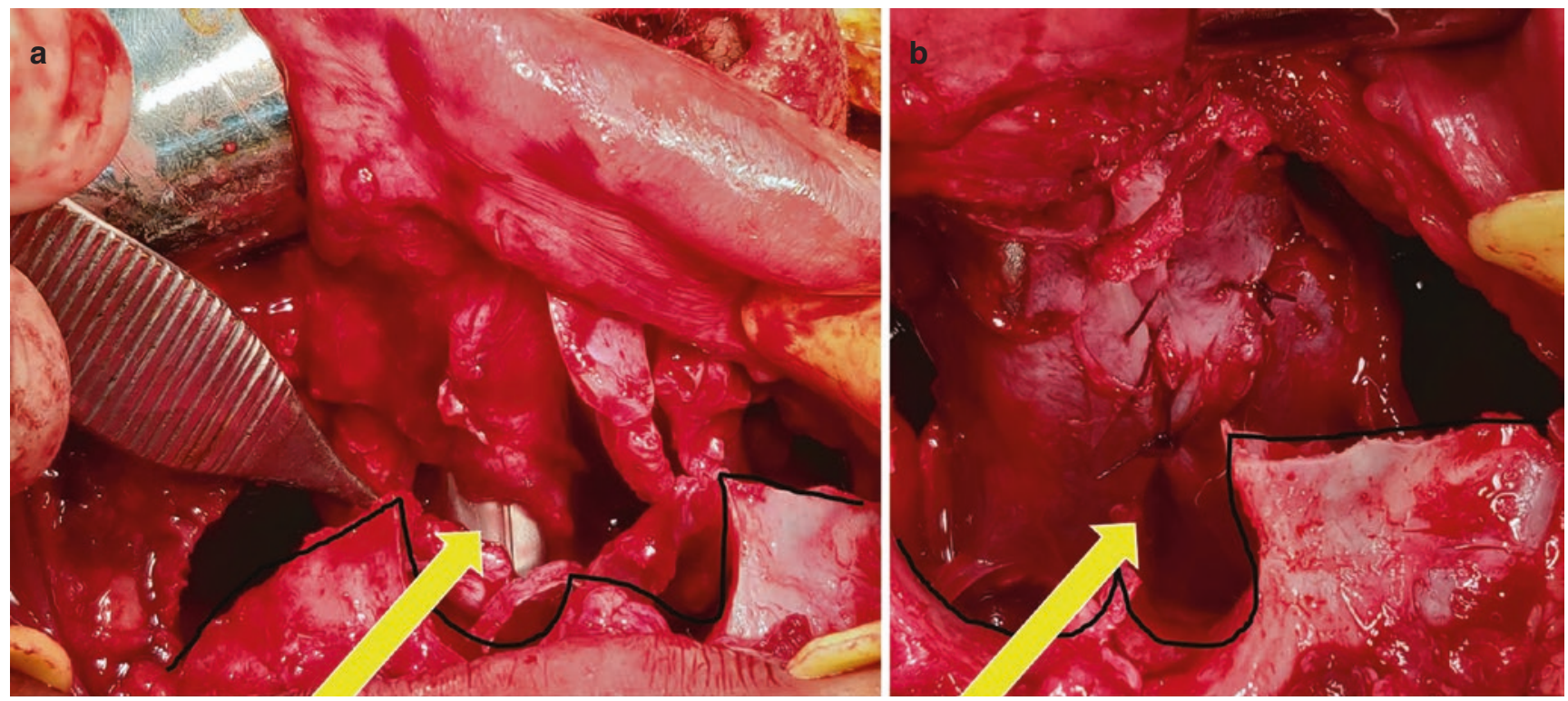

CAssociation of Oral and Maxillofacial Surgeons of India

Fig. 75.13 (a) Torn nasal floor mucosa after down-fracture of maxilla. The endotracheal tube is visible. (b) The torn edges should be sutured back to prevent postoperative bleeding 

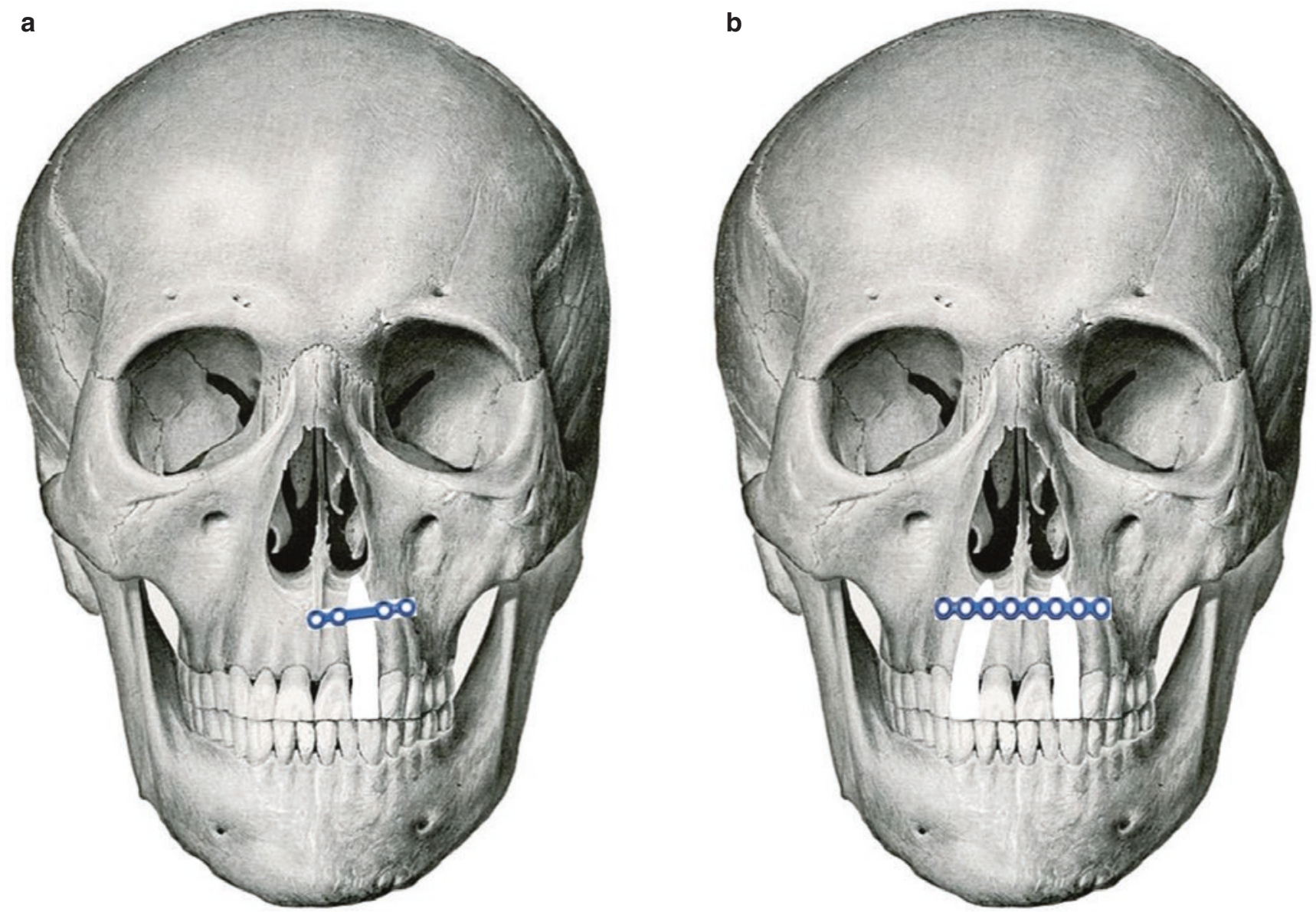

Fig. 75.14 Transverse plate across maxilla for stability during LeFort I osteotomy in a cleft. (a) Unilateral cleft of maxilla (b) Bilateral cleft of maxilla

to facilitate alveolar bone grafting or close alveolar fistulas. It can widen the maxillary arch within acceptable limits, allow differential movement of greater and lesser segments, align the occlusal plane, and maximize intercuspation to improve postoperative stability [98].

The presence of a persistent oronasal fistula and alveolar cleft defect requires careful soft tissue closure and bone grafting. One can also augment the deficient area along the lateral piriform rim on the cleft side to improve the contour of the alar base. The maxilla can fracture at the cleft alveolus site into two segments during the down-fracture and mobilization, even when the alveolar cleft site has been previously grafted. A preoperatively fabricated surgical palatal stent helps stabilize the maxilla in this situation.

Rigid fixation with mini plates and screws is preferred to stabilize the maxilla in its final position with a preference for the lateral pyriform rim and zygomaticomaxillary buttress regions as the bone here is thicker [83, 99]. One should pay attention while suturing and prevent entrapment of soft tissues into the osteotomy sites. The soft tissue of the upper lip may be tight with a shallow vestibular depth and deficient vermilion show that may become worse following maxillary advancement. "V-Y" closure can be used to reduce lip shortening.

\subsubsection{Additional Steps Performed on a Case- to-Case Basis}

\subsubsection{Deciding the Level of Midface Advancement (Fig. 75.15a-f)}

In most of the cases, a traditional LeFort I (Fig. 75.15a) osteotomy is advocated. However, in some rare instances, it may need a LeFort II (Fig. 75.15b) or LeFort III (Fig. 75.15c) osteotomy depending on the severity and the extent of the involvement. As the $\mathrm{CMH}$ involves the pyriform, the paranasal, and the zygomatic areas, though not symmetrical, the LeFort I osteotomy design in such situations may need modification to involve the para-nasal (Fig. 75.15d) and/or zygomatic (Fig. 75.15e) areas unilaterally (Fig. 75.15f) or bilaterally as the case may be. 
a
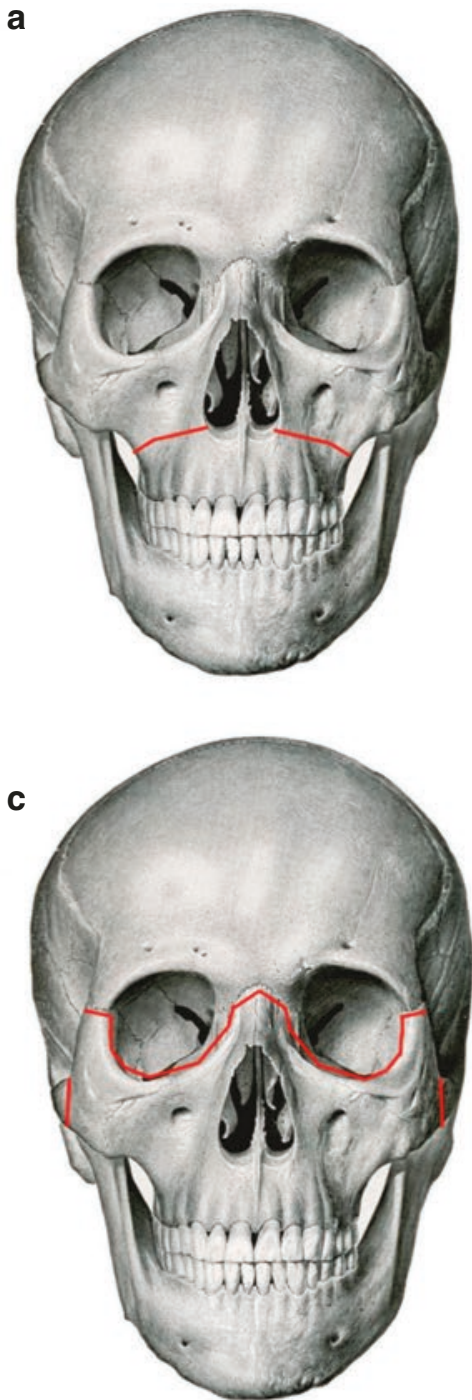

e

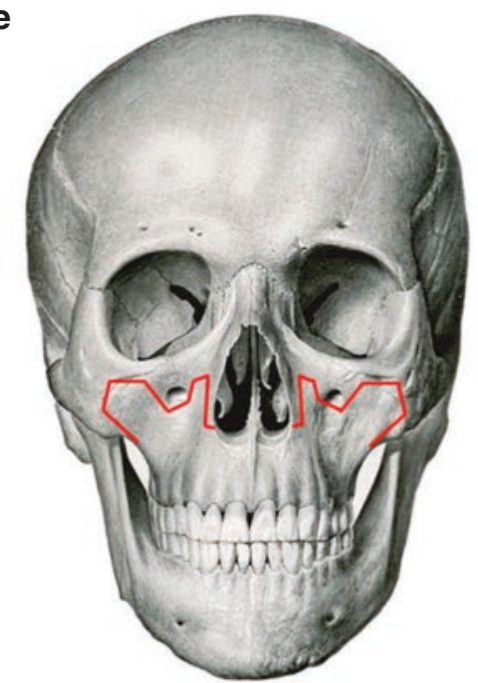

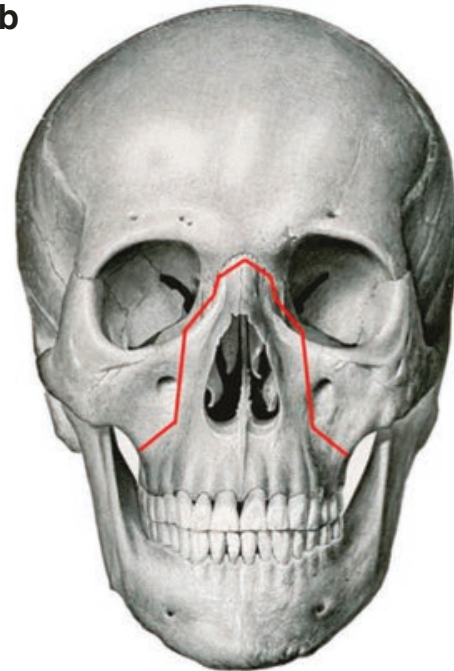

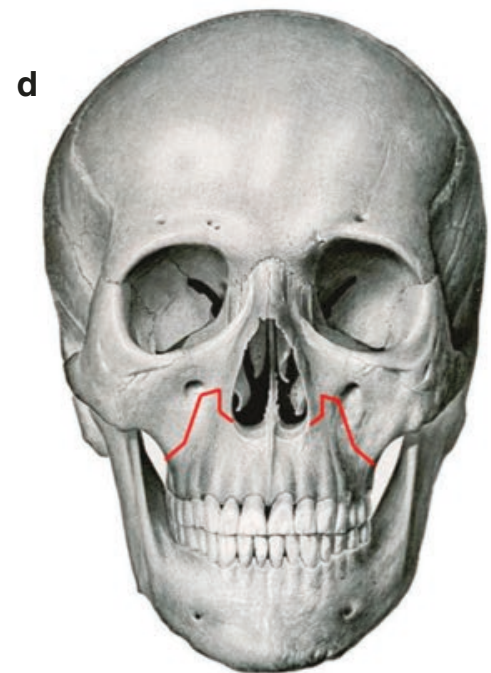

f

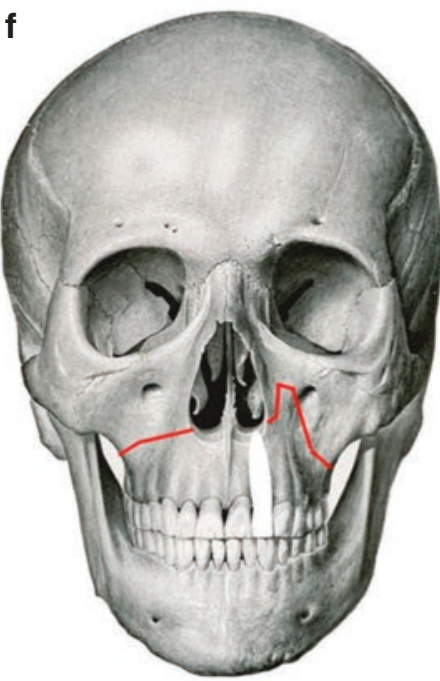

(C)Association of Oral and Maxillofacial Surgeons of India

Fig. 75.15 Levels of midface advancement (a) LeFort I, (b) LeFort II, (c) LeFort III osteotomies. Modifications of LeFort I osteotomy (d), para-nasal extension, (e) para-nasal and zygomatic extensions, and (f) conventional LeFort I on the unaffected side and para-nasal extension on the affected side 


\subsubsection{Preserving the Descending Palatine Artery}

Studies by Bell et al. established that the descending palatine artery did not contribute significantly to the re-vascularization of the maxilla after a total maxillary osteotomy in routine cases $[100,101]$. However, the greater palatine arterial network in CLP patients may become narrow and develop vascular anomalies because of the presence of scar tissue created by the palatoplasty procedure $[7,60,83]$. Considering the unique scenario of the cleft maxilla, it is advisable that efforts should be made to preserve the descending palatine artery and secure it as an additional source blood supply for the osteotomized maxilla [7, 102]. Techniques to identify and preserve the descending palatine artery have been documented in the literature [103-108]. However, the above technique needs to be tailored to the cleft maxillary anatomy as it is highly variable. Studies have established that the distance between the lateral pyriform aperture and the descending palatine artery is on an average 3-4 $\mathrm{mm}$ lesser in CLP patients. Similarly, the posterior and lateral distances to the descending palatine artery were greater on in CLP patients on account of the thickened pterygomaxillary junction [7, $83,84]$. The perpendicular process of the palatine bone surrounding the descending palatine artery is also of the dense cortical type adding to the difficulty of isolating the vessel [99]. The author reserves this step only when the patient has undergone a large number of revision surgeries in the palate.

\subsubsection{Grafting of the Osteotomy Site}

The cleft maxilla is deficient in all three dimensions, and hence its correction requires complex large movements. Cortico-cancellous bone grafts can be placed across the gap created in the region of the lateral osteotomy $[2,3,7,86$, 109]. The ideal source of autogenous bone grafting is the anterior iliac crest [110]. As an alternative, one can also use autogenous genial grafts, allogenic grafts, or synthetic hydroxyapatite bone blocks [111-114]. The author prefers to graft the osteotomy site only when down-grafting the maxilla or advancing the maxilla more than $10 \mathrm{~mm}$.

\subsection{Clinical Morbidity and Psychological Response}

According to Stork et al. and Chua et al., there was no major difference between clinical morbidity between distraction osteogenesis and orthognathic surgery and between grafted and non-grafted patients, the source of graft being the anterior iliac crest [115-117].

Patients undergoing distraction osteogenesis experienced greater levels of stress in the short term. Over time, the distraction group had a higher satisfaction with life [118-120]. This may be because of the better stability of the distraction osteogenesis in the long term as well as the self-perceived contribution of the patients to the success of their treatment. There is also an aspect of superior soft tissue response to distraction as compared to orthognathic surgery which may improve the final aesthetic result (refer Chap. 87 to read more about Distraction Osteogenesis) [121].

Nonetheless, psychological support from family and friends is recommended for patients undergoing either distraction or orthognathic surgery so as to achieve a better life satisfaction in the long term.

\subsection{Stability of Results}

The postoperative stability after orthognathic surgery in cleft patients is lower than non-cleft patients $[2,3,7,86]$. Maximum relapse in cleft orthognathic surgery occurs in the first 6 months, and the situation stabilizes 2 years postoperatively [122].

\subsubsection{Soft Tissue Envelope}

The presence of scarred tissue in the palate and the lip prevents the maxilla from being adequately mobilized. Though the maxilla might be secured into its desired position with the help of rigid fixation and bone grafting, the excess stress placed on the maxilla due to the scarred soft tissue envelope leads to relapse in both the sagittal and vertical dimensions $[2,3,7,86,123]$. The severity of labio-palatal clefting and history of multiple revision surgeries increase the risk for relapse.

\subsubsection{Magnitude of Planned Surgical Movement}

The amount of surgical movement is the most important factor that determines the degree of relapse in cleft and noncleft cases. Thus, most surgeons tend to overcorrect by an additional $20 \%$ to account for the possible relapse $[2,3,7$, $86,124]$.

However, a recent study by Watts et al. [125] suggested that amount of linear advancement was not a major cause for skeletal and dental relapse rate in cleft orthognathic. Studies by Bhatia et al. [59] and Hoffman et al. [126] suggested the same. Nonetheless, the general trend is to perform bi-jaw orthognathic surgery or distract the maxilla if more than $10 \mathrm{~mm}$ advancement is needed. 


\subsubsection{Status of Alveolar Bone Grafting}

Lack of alveolar bone grafting increases the difficulty of performing cleft orthognathic surgery. However, though alveolar bone grafting contributes to transverse stability of the maxillary arch and improve outcomes in orthodontia, it does not improve stability of sagittal, vertical, or rotational movements [122, 124].

\subsubsection{Intraoperative Factors}

Inadequate separation at the pterygomaxillary junction due to its thicker form in CLP patients, the presence of a pharyngeal flap, a shallow overbite, and the absence of multiple teeth leading to poor intercuspation may contribute to relapse as well $[2,3,7,86,124]$. Segmentation of the maxilla as compared to one-piece maxilla was not associated with greater relapse rates in CLP patients and instead could correct orthodontic and occlusal problems that were distinctive to the cleft maxilla. Nonetheless, no attempt should be made to significantly widen the cleft maxilla as using a segmental osteotomy is a highly unstable procedure $[98,127,128]$.

In the author's opinion, poor-quality bone in the cleft maxilla makes rigid fixation difficult and increases the risk for relapse $[2,3,7]$. Thus, it is advisable to always secure plates in the region of thick cortical bone, i.e., the zygomaticomaxillary buttress region posteriorly and the lateral pyriform aperture anteriorly (Fig. 75.16a-c). Bony fenestrations can be encountered in cases with prior AMD during maxillary orthognathic surgery; extra care must be taken during plating the same (Fig. 75.17).
Owing to the large advancements commonly performed in cleft orthognathic surgery, the gap between the osteotomized segments is large. When the contact area between the bony shelves is small, there may be instability or fibrous union between segments which increases the risk for relapse. By grating these gaps, there is increased bony contact which helps in optimal healing. Rarely, the space posterior to the maxillary tuberosity after advancement of the maxilla is also grafted to help prevent relapse [46]. Owing to the hostile environment of the cleft maxilla, it is general consensus that autogenous bone grafts provide the best results in terms of take up of the graft and significantly lower complication rates. It is interesting to note that a recent study by Stork et al. [115] suggested that grafting was not a major factor in preventing postoperative skeletal relapse in cleft and noncleft patients contrary to the currently accepted methodology. A study by Hoffman et al. [129] in non-cleft patients suggested the same. The author's opinion is in line with both the above authors and grafts the osteotomy site only when advancing the maxilla more than $10 \mathrm{~mm}$ or down-grafting the maxilla.

\subsubsection{Timing of Surgery}

As previously mentioned, surgery performed before skeletal maturity is associated with a higher relapse rate in both horizontal and vertical dimensions due to continued growth. This is applicable irrespective of the type of surgery being performed: orthognathic surgery or distraction osteogenesis [21, $23,24]$. Secondary surgery for the correction of residual growth deformities is required after growth is complete. It is

\section{Fenestrations / Weak Bone}

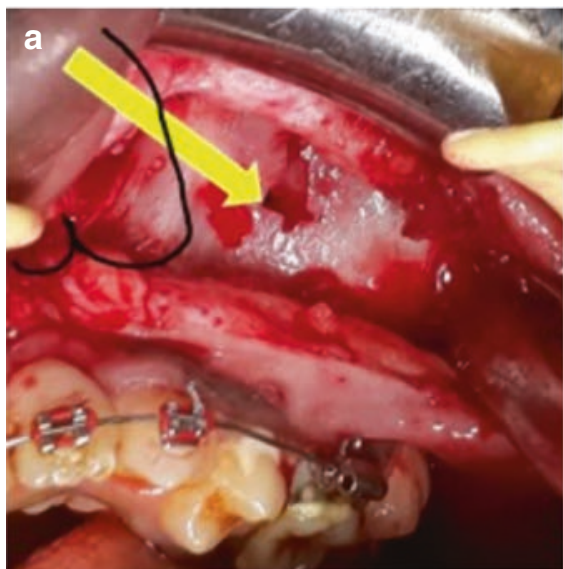

Bone along osteotomy line fractured \& displaced into sinus

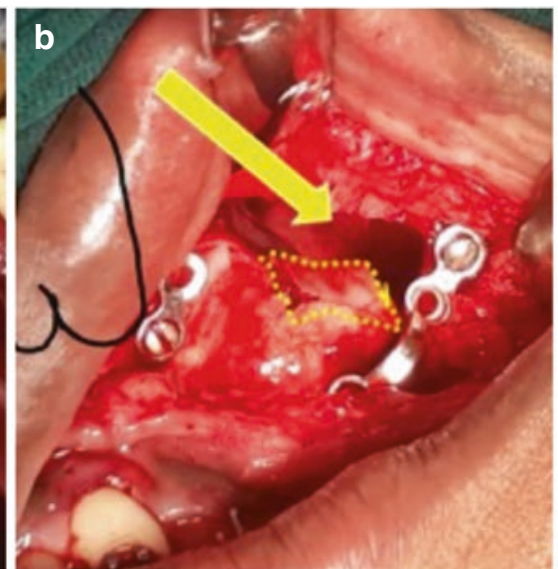

Plating Design Along Pyriform Rim and Zygoma-Maxillary Buttress

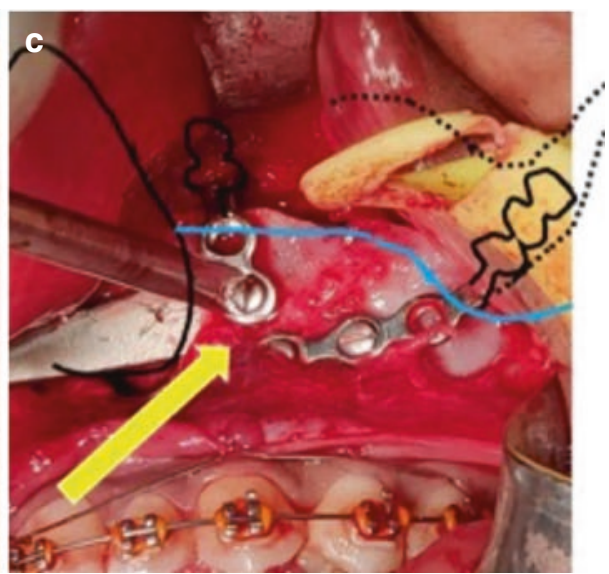

CAssociation of Oral and Maxillofacial Surgeons of India

Fig. 75.16 (a-c) Poor-quality bone seen in the anterolateral and posterolateral walls of the maxilla. Always plate along the lateral pyriform rim and zygomamaxillary buttress (dotted) region which are known to have good-quality bone. Part of the miniplate obscured by the retractor and tissues has been traced for better understanding of the plate position. Blue line denotes line of osteotomy on the dental side 


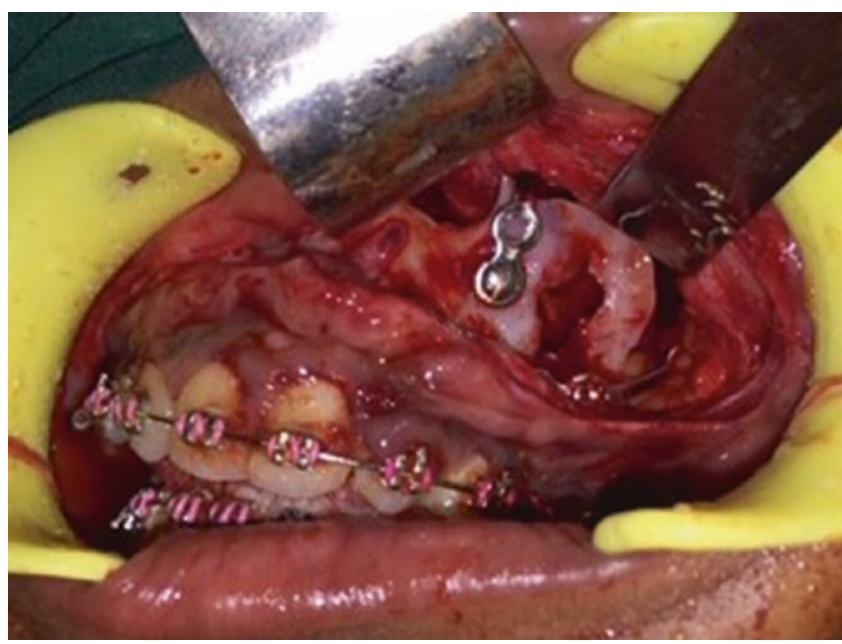

CAssociation of Oral and Maxillofacial Surgeons of India

Fig. 75.17 Large bony fenestration in anterolateral wall of the maxilla at the time of orthognathic surgery. It is commonly found where prior anterior maxillary distraction was done. The presence of such a large fenestration can make plating difficult

important to note that distraction osteogenesis was more commonly preferred in the growing patient $[2,3,7,22,130,131]$.

\subsubsection{Degree of Relapse}

A review by Kloukos et al. [120] established that results obtained with distraction osteogenesis were more stable as compared to conventional orthognathic surgery 5 years postoperatively. A review by Saltaji et al. [132, 133] reported average horizontal relapse rates of $10 \%$ in distraction cases and $25-30 \%$ in orthognathic cases for cleft patients. Vertical relapse rates in cleft orthognathic patients were high with an average rate of 40-50\%. Similar results have been documented in other studies and reviews with up to 5-year followups [134-140]. The rate for re-operation in cleft orthognathic surgery was approximately $12.2 \%$ [140]. Internal distractors were also found to be more stable than external distractors. This can be attributed to the rigidity provided by the internal distractor during the consolidation phase. The use of rigid fixation with miniplates was attributed with the least amount of relapse in cleft orthognathic surgery [2, 3, 7, 132].

Based on the above evidence, distraction osteogenesis has become the mainstay for the management of severe to extreme cleft maxillary hypoplasia (reverse overjet greater than $11 \mathrm{~mm}$ ) as the slow distraction of bone and the accompanying histogenic abilities help reduce skeletal relapse. Orthognathic surgery is preferred for mild to moderate cleft maxillary hypoplasia (reverse overjet lesser than $11 \mathrm{~mm})$.

\subsubsection{Clinical Suggestions to Avoid Relapse}

Commonly used methods to prevent or control relapse are as follows: overcorrection of the final surgical result by $20 \%$, prolonged intermaxillary fixation during the postoperative phase, using face masks with reverse traction of the maxilla, interpositioning bone grafts between the gaps created by maxillary advancement, and performing bi-jaw surgery or distraction when advancements greater than $10 \mathrm{~mm}$ are required [114]. A study by Tabrizi et al. [141] established that the use of rigid fixation after the consolidation phase of cleft maxillary distraction did not increase stability of results. In anterior maxillary distraction, it is essential to lock the appliance with wire or acrylic plug during the consolidation phase to prevent backward rotation of the hyrax screw.

\subsection{Complications}

A study by Metalwala et al. [142] established that there is increased risk for infection and prolonged hospital stay in patients with craniofacial anomalies undergoing orthognathic surgery. The incidence of complications in non-cleft patients has been reported at $6.4 \%$ as compared to $25.2 \%$ in cleft patients [83].

Studies by Yamaguchi et al. [140] and Moran et al. [143] revealed that an average of 15-30\% of patients present with perioperative complications. The most common complications were closure failure of pre-existing palatal fistula, velopharyngeal impairment, temporary paresthesia of the infra-orbital nerve, and surgical site infection. A review by Santos et al. [144] established that cleft maxilla patients present with the highest incidence of cranial nerve damage on account of the anatomically higher modified LeFort I osteotomy cut and excessive forces needed at the time of pterygomaxillary dysjunction. Rare and severe complications like arteriovenous fistula, maxillary aneurysm, cavernous sinus thrombosis, skull base fractures, and maxillary necrosis blindness are more common among patients with craniofacial anomalies but have an incidence of lesser than $0.5 \%$ [140, 143, 145]. It has been suggested by Eduardo et al. [146] that the use of piezo-electric surgical instruments in orthognathic surgery is associated with a lower complication rate.

With the author's experience (PM) of approximately 900 cleft orthognathic cases while using the traditional dysjunction technique, there has been no major vascular complication or skull base fractures. However, two patients experienced transient blindness with partial recovery of vision in the long term [79]. 


\subsection{Conclusion}

Skeletal surgery is a critical component of surgical management of CLP. On account of the unique anatomy of the cleft maxilla that has been subjected to previous lip \& palate interventions, the conventional LeFort I osteotomy technique and orthognathic surgical principles need to be adapted accordingly. The ultimate goal of treatment should be to achieve intelligible speech and an acceptable appearance with good balance of facial skeleton, soft tissues, and occlusion. Distraction osteogenesis is a useful technique in the management of severe maxillary deficiency, but does not replace conventional orthognathic surgery. Maxillofacial surgeons who treat these deformities should be part of a craniofacial team to provide interdisciplinary care for the patient. The aim of the team should be to help the child to develop into a confident young adult.

Acknowledgment Dr. Rahul Tiwari (M.D.S Oral and Maxillofacial Surgery) for manuscript preparation

Designation: Fellow of Orthognathic Surgery

Institutional Address with pin code: Jubilee Mission Medical College and Hospital, Thrissur 680005

\section{References}

1. Shetye PR. Facial growth of adults with unoperated clefts. Clin Plast Surg. 2004;31(2):361-71

2. Chigurupati R. Orthognathic surgery for secondary cleft and craniofacial deformities. Oral Maxillofac Surg Clin North Am. 2005;17(4):503-17.

3. Posnick JC, Ricalde P. Cleft-orthognathic surgery. Clin Plast Surg. 2004;31(2):315-30.

4. Oberoi S, Chigurupati R, Vargervik K. Morphologic and management characteristics of individuals with unilateral cleft lip and palate who required maxillary advancement. Cleft Palate Craniofac J. 2008;45(1):42-9.

5. Oberoi S, Hoffman WY, Chigurupati R, Vargervik K. Frequency of surgical correction for maxillary hypoplasia in cleft lip and palate. $\mathrm{J}$ Craniofac Surg. 2012;23(6):1665-7.

6. Good PM, Mulliken JB, Padwa BL. Frequency of Le Fort I osteotomy after repaired cleft lip and palate or cleft palate. Cleft Palate Craniofac J. 2007;44(4):396-401.

7. Chigurupati R. Cleft lip and palate: Timing and approaches to reconstruction. In: Saunder, editor. Current therapy in oral and maxillofacial surgery. 1st ed. Elsevier; 2012. p. 726-50.

8. Jones CM, Mackay AFJ, Mackay DR, Long RE. Do pharyngeal flaps restrict early midface growth in patients with clefts? Cleft Palate Craniofacial J. 2016;53(6):629-33.

9. Abyholm FE, Otaki S. Cleft lip and palate. 3rd ed. Berkowitz S, editor. Berlin: Springer; 2013. p. 601-12.

10. Gopinath VK, Samsudin AR, Noor SNFM, Sharab HYM. Facial profile and maxillary arch dimensions in unilateral cleft lip and palate children in the mixed dentition stage. Eur J Dent 2018;11(1):76-82.

11. Lee Y, Liao Y. Hard palate-repair technique and facial growth in patients with cleft lip and palate: a systematic review. Br J Oral Maxillofac Surg. 2013;51(8):851-7.
12. Campbell A, Costello BJ, Ruiz RL. Cleft lip and palate surgery: an update of clinical outcomes for primary repair. Oral Maxillofac Surg Clin North Am. 2010;22(1):43-58.

13. Yang I, Liao Y. Cleft lip and palate the effect of 1-stage versus 2-stage palate repair on facial growth in patients with cleft lip and palate: a review. Int J Oral Maxillofac Surg. 2010;39(10):945-50.

14. Stein S, Dunsche A, Gellrich NC, Härle F, Jonas I. One- or twostage palate closure in patients with unilateral cleft lip and palate: Comparing cephalometric and occlusal outcomes. Cleft Palate Craniofac J. 2007;44(1):13-22.

15. Xu X, Kwon HJ, Shi B, Zheng Q, Yin H, Li C. Influence of different palate repair protocols on facial growth in unilateral complete cleft lip and palate. J Cranio Maxillofac Surg. 2015;43(1):43-7.

16. Santiago PE, Schuster LA, Levy-Bercowski D. Management of the alveolar cleft. Clin Plast Surg. 2014;41(2):219-32.

17. Da Silva Filho OG, Boiani E, Cavassan ADO, Santamaria M. Rapid maxillary expansion after secondary alveolar bone grafting in patients with alveolar cleft. Cleft Palate Craniofac J. 2009;46(3):331-8.

18. Emodi O, Noy D, Hazan-Molina H, Aizenbud D, Rachmiel A. Secondary bone grafting of the cleft maxilla following reverse quad-helix expansion in 103 patients. Ann Maxillofac Surg. 2015;5(1):32.

19. Uzel A, Benlidayı ME, Kürkçü M, Kesiktaş E. The effects of maxillary expansion on late alveolar bone grafting in patients with unilateral cleft lip and palate. J Oral Maxillofac Surg. 2019;77(3):607-14.

20. Reyneke JP, Tsakiris P, Becker P. Age as a factor in the complication rate after removal of unerupted/impacted third molars at the time of mandibular sagittal split osteotomy. J Oral Maxillofac Surg. 2002;60(6):654-9.

21. Wolford LM, Cassano DS, Cottrell DA, El Deeb M, Karras SC, Goncalves JR. Orthognathic surgery in the young cleft patient: preliminary study on subsequent facial growth. J Oral Maxillofac Surg. 2008;66(12):2524-36.

22. Wolford LM, Karras SC, Mehra P. Considerations for orthognathic surgery during growth, Part 2: Maxillary deformities. Am J Orthod Dentofac Orthop. 2001;119(2):95-101.

23. Meazzini MC, Basile V, Mazzoleni F, Bozzetti A, Brusati R. Longterm follow-up of large maxillary advancements with distraction osteogenesis in growing and non-growing cleft lip and palate patients. J Plast Reconstr Aesthetic Surg. 2015;68(1):79-86.

24. Liu K, Zhou N. Long-term skeletal changes after maxillary distraction osteogenesis in growing children with cleft lip/palate. J Craniofac Surg. 2018;29(4):e349-52.

25. Turvey TA, Golden BA, Brookes CD. Techniques in bone grafting of cleft maxilla. In: Saunders, editor. Atlas of oral and maxillofacial surgery. 1st ed. 2015. p. 569-78.

26. Dempf R, Teltzrow T, Kramer F-J, Hausamen J-E. Alveolar bone grafting in patients with complete clefts: a comparative study between secondary and tertiary bone grafting. Cleft Palate Craniofac J. 2002;39(1):18-25.

27. Kaura AS, Srinivasa DR, Kasten SJ. Optimal timing of alveolar cleft bone grafting for maxillary clefts in the cleft palate population. J Craniofac Surg. 2018;29(6):1551-7.

28. Posnick JC, Tompson B. Modification of the maxillary Le Fort I osteotomy in cleft-orthognathic surgery: The bilateral cleft lip and palate deformity. J Oral Maxillofac Surg. 1993;51(1):2-11.

29. Posnick JC, Tompson B. Modification of the maxillary Le Fort I osteotomy in cleft-orthognathic surgery: the unilateral cleft lip and palate deformity. J Oral Maxillofac Surg. 1992;50(7):666-75. Discussion 675-6

30. Posnick JC, Tompson B. Cleft-orthognathic surgery: complications and long-term results. Plast Reconstr Surg. 1995;96(2):255-66.

31. Glade RS, Deal R. Diagnosis and management of velopharyngeal dysfunction. Oral Maxillofac Surg Clin North Am. 2016;28(2):181-8. 
32. Chua HDP, Whitehill TL, Samman N, Cheung LK. Maxillary distraction versus orthognathic surgery in cleft lip and palate patients: effects on speech and velopharyngeal function. Int J Oral Maxillofac Surg. 2010;39(7):633-40.

33. Pereira VJ, Sell D, Tuomainen J. Effect of maxillary osteotomy on speech in cleft lip and palate: Perceptual outcomes of velopharyngeal function. Int J Lang Commun Disord. 2013;48(6):640-50.

34. O'Gara M, Wilson K. The effects of maxillofacial surgery on speech and velopharyngeal function. Clin Plast Surg. 2007;34(3):395-402.

35. Janulewicz J, Costello BJ, Buckley MJ, Ford MD, Close J, Gassner R. The effects of Le Fort I osteotomies on velopharyngeal and speech functions in cleft patients. J Oral Maxillofac Surg. 2004;62(3):308-14.

36. Wu Y, Wang X, Ma L, Li Z. Velopharyngeal configuration changes following Le Fort I osteotomy with maxillary advancement in patients with cleft lip and palate: A cephalometric study. Cleft Palate Craniofac J. 2015;52(6):711-6.

37. McComb RW, Marrinan EM, Nuss RC, Labrie RA, Mulliken JB, Padwa BL. Predictors of velopharyngeal insufficiency after Le Fort i maxillary advancement in patients with cleft palate. J Oral Maxillofac Surg. 2011;69(8):2226-32.

38. Chanchareonsook N, Samman N, Whitehill TL. The effect of cranio-maxillofacial osteotomies and distraction osteogenesis on speech and velopharyngeal status: A critical review. Cleft Palate Craniofac J. 2006;43(4):477-87.

39. Satoh K, Nagata J, Shomura K, Wada T, Tachimura T, Fukuda $\mathrm{J}$, et al. Morphological evaluation of changes in velopharyngeal function following maxillary distraction in patients with repaired cleft palate during mixed dentition. Cleft Palate Craniofac J. 2004;41(4):355-63.

40. Phillips JH, Klaiman P, Delorey R, MacDonald DB. Predictors of velopharyngeal insufficiency in cleft palate orthognathic surgery. Plast Reconstr Surg. 2005;115(3):681-6.

41. Alaluusua S, Turunen L, Saarikko A, Geneid A, Leikola J, Heliövaara A. The effects of Le Fort I osteotomy on velopharyngeal function in cleft patients. J Cranio Maxillofac Surg. 2019;47(2):239-44.

42. Smedberg E, Neovius E, Lohmander A. Impact of maxillary advancement on speech and velopharyngeal function in patients with cleft lip and palate. Cleft Palate Craniofac J. 2014;51(3):334-43.

43. Kim SK, Kim JC, Moon JB, Lee KC. Perceptual speech assessment after maxillary advancement osteotomy in patients with a repaired cleft lip and palate. Arch Plast Surg. 2012;39(3):198-202.

44. Schultz KP, Braun TL, Hernandez C, Wilson KD, Moore EE, Wirthlin JO, et al. Speech outcomes after LeFort I advancement among cleft lip and palate patients. Ann Plast Surg. 2019;82(2):174-9.

45. Trindade IEK, Yamashita RP, Suguimoto RM, Mazzottini R, Trindade AS. Effects of orthognathic surgery on speech and breathing of subjects with cleft lip and palate: Acoustic and aerodynamic assessment. Cleft Palate Craniofac J. 2003;40(1):54-64.

46. Poole MD, Robinson PP, Nunn ME. Maxillary advancement in cleft palate patients. Plast Reconstr Surg. 1987;80(1):154.

47. James DR, Brook K. Maxillary hypoplasia in patients with cleft lip and palate deformity-the alternative surgical approach. Eur J Orthod. 1985;7(4):231-47.

48. Richardson S, Seelan NS, Selvaraj D, Khandeparker R V., Gnanamony S. Perceptual speech assessment after anterior maxillary distraction in patients with cleft maxillary hypoplasia. J Oral Maxillofac Surg. 2016;74(6):1239.e1-9.

49. Richardson S, Agni NA, Selvaraj D. Anterior maxillary distraction using a tooth-borne device for hypoplastic cleft maxillas-a pilot study. J Oral Maxillofac Surg. 2011;69(12):e542-8.

50. Richardson S, Krishna S, Bansal A. Use of repeat anterior maxillary distraction to correct residual midface hypoplasia in cleft patients. J Korean Assoc Oral Maxillofac Surg. 2018;43(6):407.
51. Richardson S, Selvaraj D, Khandeparker R V, Seelan NS, Richardson S. Tooth-borne anterior maxillary distraction for cleft maxillary hypoplasia: our experience with 147 patients. J Oral Maxillofac Surg. 2016;74(12):2504.e1-14.

52. Richardson S, Krishna S, Khandeparker RV. A comprehensive management protocol to treat cleft maxillary hypoplasia. J Cranio Maxillofacial Surg. 2018;46(2):356-61.

53. Tahmasbi S, Jamilian A, Showkatbakhsh R, Pourdanesh F, Behnaz M. Cephalometric changes in nasopharyngeal area after anterior maxillary segmental distraction versus Le Fort I osteotomy in patients with cleft lip and palate. Eur J Dent. 2018;12(3):393-7.

54. Takahashi K, Dahy KG, Saito K, Masuoka H, Suzuki S, Bessho K. Patient with cleft maxillary hypoplasia who underwent distraction osteogenesis and conservative therapies to postoperative velopharyngeal insufficiency. J Craniofac Surg. 2017;28(5):1302-4.

55. Gart MS, Gosain AK. Surgical management of velopharyngeal insufficiency. Clin Plast Surg. 2014;41(2):253-70.

56. Denadai R, Sabbag A, Raposo-Amaral CE, Filho JCP, Nagae MH, Raposo-Amaral CA. Bilateral buccinator myomucosal flap outcomes in nonsyndromic patients with repaired cleft palate and velopharyngeal insufficiency. J Plast Reconstr Aesthetic Surg. 2017;70(11):1598-607.

57. Abdel-Aziz M, Hussien A, Kamel A, Azooz K, Fawaz M. The impact of velopharyngeal surgery on the polysomnographic parameters after cleft palate repair. J Craniofac Surg. 2018;29(3):717-9.

58. Dentino KM, Marrinan EM, Brustowicz K, Mulliken JB, Padwa BL. Pharyngeal flap is effective treatment for post maxillary advancement velopharyngeal insufficiency in patients with repaired cleft lip and palate. J Oral Maxillofac Surg. 2016;74(6):1207-14.

59. Bhatia S, Bocca A, Jones J, Sugar AW. Le Fort I advancement osteotomies of $1 \mathrm{~cm}$ or more. How safe or stable? Br J Oral Maxillofac Surg. 2016;54(3):346-50.

60. Drommer R. Selective angiographic studies prior to Le Fort I osteotomy in patients with cleft lip and palate. J Maxillofac Surg. 1979;7(C):264-70.

61. Rachmiel A. Treatment of maxillary cleft palate: distraction osteogenesis versus orthognathic surgery-part one: maxillary distraction. J Oral Maxillofac Surg. 2007;65(4):753-7.

62. Rachmiel A, Even-Almos M, Aizenbud D. Treatment of maxillary cleft palate: Distraction osteogenesis vs. orthognathic surgery. Ann Maxillofac Surg. 2012;2(2):127-30.

63. Zhang Y, Jia H, Fu Z, Huang Y, Wang Z, Guo R, et al. Dentoskeletal effects of facemask therapy in skeletal Class III cleft patients with or without bone graft. Am J Orthod Dentofac Orthop. 2018;153(4):542-9.

64. Ahn HW, Kim KW, Yang IH, Choi JY, Baek SH. Comparison of the effects of maxillary protraction using facemask and miniplate anchorage between unilateral and bilateral cleft lip and palate patients. Angle Orthod. 2012;82(5):935-41.

65. Zhang Y, Fu Z, Jia H, Huang Y, Li X, Liu H, et al. Long-term stability of maxillary protraction therapy in Class III patients with complete unilateral cleft lip and palate. Angle Orthod. 2019;89(2):214-20.

66. Tindlund RS. Skeletal response to maxillary protraction in patients with cleft lip and palate before age 10 years. Cleft Palate Craniofac J. 1994;31(4):295-308.

67. Angelieri F, Franchi L, Cevidanes LHS, Hino CT, Nguyen T, McNamara JA. Zygomaticomaxillary suture maturation: A predictor of maxillary protraction? Part I-A classification method. Orthod Craniofac Res. 2017;20(2):85-94.

68. Angelieri F, Ruellas AC, Yatabe MS, Cevidanes LHS, Franchi L, Toyama-Hino $\mathrm{C}$, et al. Zygomaticomaxillary suture maturation: Part II-The influence of sutural maturation on the response to maxillary protraction. Orthod Craniofac Res. 2017;20(3):152-63.

69. Hino CT, Cevidanes LHS, Nguyen TT, De Clerck HJ, Franchi L, McNamara JA. Three-dimensional analysis of maxillary changes 
associated with facemask and rapid maxillary expansion compared with bone anchored maxillary protraction. Am J Orthod Dentofac Orthop. 2013;144(5):705-14.

70. On SW, Baek SH, Choi JY. Effect of long-term use of facemask with miniplate on maxillary protraction in patients with cleft lip and palate. J Craniofac Surg. 2018;29(2):309-14.

71. Jahanbin A, Kazemian M, Eslami N, Pouya IS. Maxillary protraction with intermaxillary elastics to miniplates versus bone-anchored face-mask therapy in cleft lip and palate patients. J Craniofac Surg. 2016;27(5):1247-52.

72. Faco R, Yatabe M, Cevidanes LHS, Timmerman H, De Clerck HJ, Garib D. Bone-anchored maxillary protraction in unilateral cleft lip and palate: a cephalometric appraisal. Eur J Orthod. 2019:1-7.

73. Susami T, Mori Y, Ohkubo K, Takahashi M, Hirano Y, Saijo H, et al. Changes in maxillofacial morphology and velopharyngeal function with two-stage maxillary distraction-mandibular setback surgery in patients with cleft lip and palate. Int J Oral Maxillofac Surg. 2018;47(3):357-65.

74. Dan AEB, Thygesen TH, Pinholt EM. Corticosteroid administration in oral and orthognathic surgery: A systematic review of the literature and meta-analysis. J Oral Maxillofac Surg. 2010;68(9):2207-20.

75. Jean S, Dionne PL, Bouchard C, Giasson L, Turgeon AF. Perioperative systemic corticosteroids in orthognathic surgery: a systematic review and meta-analysis. J Oral Maxillofac Surg. 2017;75(12):2638-49.

76. Olsen JJ, Skov J, Ingerslev J, Thorn JJ, Pinholt EM. Prevention of bleeding in orthognathic surgery-A systematic review and metaanalysis of randomized controlled trials. J Oral Maxillofac Surg. 2016; 74:139-150.

77. Choi WS, Samman N. Risks and benefits of deliberate hypotension in anaesthesia: a systematic review. Int J Oral Maxillofac Surg. 2008;37(8):687-703.

78. Rodríguez-Navarro A, Gonzalez-Valverde FM. Unilateral blindness after orthognathic surgery: hypotensive anaesthesia is not the primary cause. Int J Oral Maxillofac Surg. 2018;47(1):79-82.

79. Mathew P, Adenwalla HS, Narayanan PV, Nyamu E. A report of 2 patients with transient blindness following Le Fort I osteotomy and a review of past reported cases. Indian J Plast Surg. 2015;48(3):297-300.

80. Lo L-J, Hung K-F, Chen Y-R. Blindness as a complication of Le Fort I osteotomy for maxillary distraction. Plast Reconstr Surg. 2002;109(2):688-98. Discussion 699-700

81. Ettinger KS, Yildirim Y, Weingarten TN, Van Ess JM, Viozzi CF, Arce K. Hypotensive anesthesia is associated with shortened length of hospital stay following orthognathic surgery. J Oral Maxillofac Surg. 2016;74(1):130-8.

82. Lin S, McKenna SJ, Yao CF, Chen YR, Chen C. Effects of hypotensive anesthesia on reducing intraoperative blood loss, duration of operation, and quality of surgical field during orthognathic surgery: a systematic review and meta-analysis of randomized controlled trials. J Oral Maxillofac Surg. 2017;75:73-86.

83. Watanabe M, Watanabe A, Takano N, Saito C, Shibahara T. Morphologic evaluation for safe le fort I osteotomy in cleft lip and palate. Cleft Palate Craniofac J. 2018;55(5):728-35.

84. Lee SH, Lee SH, Mori Y, Minami K, Park HS, Kwon TG. Evaluation of pterygomaxillary anatomy using computed tomography: Are there any structural variations in cleft patients? J Oral Maxillofac Surg. 2011;69(10):2644-9.

85. Hoffman GR, Islam S. The difficult Le Fort I osteotomy and downfracture: a review with consideration given to an atypical maxillary morphology. J Plast Reconstr Aesthetic Surg. 2008;61(9):1029-33.

86. Phillips JH, Nish I, Daskalogiannakis J. Orthognathic surgery in cleft patients. Plast Reconstr Surg. 2012;129(3):535e-48e.
87. Precious DS, Goodday RH, Bourget L, Skulsky FG. Pterygoid plate fracture in Le Fort I osteotomy with and without pterygoid chisel: a computed tomography scan evaluation of 58 patients. J Oral Maxillofac Surg. 1993;51(2):151-3.

88. Precious DS, Morrison A, Ricard D. Pterygomaxillary separation without the use of an osteotome. J Oral Maxillofac Surg. 1991;49(1):98-9.

89. Turvey TA, Fonseca RJ. The anatomy of the internal maxillary artery in the pterygopalatine fossa: its relationship to maxillary surgery. J Oral Surg. 1980;38(2):92-5.

90. Laster Z, Ardekian L, Rachmiel A, Peled M. Use of the "sharkfin" osteotome in separation of the pterygomaxillary junction in Le Fort I osteotomy: A clinical and computerized tomography study. Int J Oral Maxillofac Surg. 2002;31(1):100-3.

91. Trimble LD, Tideman H, Stoelinga PJW. A modification of the pterygoid plate separation in low-level maxillary osteotomies. J Oral Maxillofac Surg. 1983;41(8):544-6.

92. Kanazawa T, Kuroyanagi N, Miyachi H, Ochiai S, Kamiya N, Nagao T, et al. Factors predictive of pterygoid process fractures after pterygomaxillary separation without using an osteotome in le Fort i osteotomy. Oral Surg Oral Med Oral Pathol Oral Radiol. 2013;115(3):310-8.

93. Breeze J, Linares CV, Stockton P. Is an osteotome necessary for pterygomaxillary dysjunction or dysjunction through the tuberosity during le Fort i osteotomy? A systematic review. Br J Oral Maxillofac Surg. 2016;54:248-52.

94. Dadwal H, Shanmugasundaram S, Krishnakumar Raja VB. Preoperative and postoperative CT scan assessment of pterygomaxillary junction in patients undergoing Le Fort I osteotomy: comparison of pterygomaxillary dysjunction technique and Trimble technique-a pilot study. J Maxillofac Oral Surg. 2015;14(3):713-9.

95. Hernández-Alfaro F, Guijarro-Martínez R. "Twist technique” for pterygomaxillary dysjunction in minimally invasive Le Fort I osteotomy. J Oral Maxillofac Surg. 2013;71(2):389-92.

96. Ueki K, Nakagawa K, Marukawa K, Yamamoto E. Le Fort I osteotomy using an ultrasonic bone curette to fracture the pterygoid plates. J Cranio Maxillofac Surg. 2004;32(6):381-6.

97. Ueki K, Hashiba Y, Marukawa K, Okabe K, Alam S, Nakagawa $\mathrm{K}$, et al. Assessment of pterygomaxillary separation in Le Fort I osteotomy in class III patients. J Oral Maxillofac Surg. 2009;67(4):833-9.

98. Watts GD, Antonarakis GS, Forrest CR, Tompson BD, Phillips JH. Single versus segmental maxillary osteotomies and long-term stability in unilateral cleft lip and palate related malocclusion. $\mathbf{J}$ Oral Maxillofac Surg. 2014;72(12):2514-21.

99. James JN, Costello BJ, Ruiz RL. Management of cleft lip and palate and cleft orthognathic considerations. Oral Maxillofac Surg Clin North Am. 2014;26(4):565-72.

100. Bell WH, Fonseca RJ, Kenneky JW, Levy BM. Bone healing and revascularization after total maxillary osteotomy. J Oral Surg. 1975;33(4):253-60.

101. Bell WH, Levy BM. Revascularization and bone healing after maxillary corticotomies. J Oral Surg. 1972;30(9):640-8.

102. Lanigan DT. Ligation of the descending palatine artery: pro and con. J Oral Maxillofac Surg. 1997;55(12):1502-4.

103. Regan BO, Bharadwaj G. The identification and protection of the descending palatine artery in Le Fort I osteotomy: a forgotten technique? Br J Oral Maxillofac Surg. 2007;45(5):412-4.

104. Omura S, Iwai T, Honda K, Shibutani N, Fujita K, Yamashita Y, et al. U-shaped osteotomy around the descending palatine artery to prevent posterior osseous interference for superior/posterior repositioning of the maxilla in le Fort i osteotomy. J Craniofac Surg. 2015;26(5):1613-5.

105. Omura S, Iwai T, Murata S, Tohnai I. Use of a simple handmade retractor to protect the descending palatine artery during removal 
of posterior osseous interferences for maxillary impaction in le fort i osteotomy. J Craniofac Surg. 2013;24(3):978-9.

106. Johnson LM, Arnett GW. Pyramidal osseous release around the descending palatine artery: a surgical technique. J Oral Maxillofac Surg. 1991;49(12):1356-7.

107. Betts NJ, Fonseca RJ. Location of the descending palatine artery in relation to the Le Fort I osteotomy. J Oral Maxillofac Surg. 1996;54(7):826-7.

108. Li KK, Meara JG, Alexander A. Location of the descending palatine artery in relation to the Le Fort I osteotomy. J Oral Maxillofac Surg. 1996;54(7):822-5.

109. Waite PD, Tejera TJ, Anucul B. The stability of maxillary advancement using Le Fort I osteotomy with and without genial bone grafting. Int J Oral Maxillofac Surg. 1996;25(4):264-7.

110. Posnick JC, Gray JA. Is it safe to re-harvest the anterior iliac crest to manage Le Fort I interpositional defects in young adults with a repaired cleft? J Oral Maxillofac Surg. 2015;73(12):S32-9.

111. Wardrop RW, Wolford LM. Maxillary stability following downgraft and/or advancement procedures with stabilization using rigid fixation and porous block hydroxyapatite implants. J Oral Maxillofac Surg. 1989;47(4):336-42.

112. Mehra P, Castro V, Freitas RZ, Wolford LM. Stability of the Le Fort I osteotomy for maxillary advancement using rigid fixation and porous block hydroxyapatite grafting. Oral Surg Oral Med Oral Pathol Oral Radiol Endod. 2002;94(1):18-23.

113. Mehra P, Wolford LM, Hopkin JK, Castro V, Frietas R. Stability of maxillary advancement using rigid fixation and porous-block hydroxyapatite grafting: cleft palate versus non-cleft patients. Int J Adult Orthodon Orthognath Surg. 2001;16(3):193-9.

114. Gomes KU, Martins WDB, Ribas M de O. Horizontal and vertical maxillary osteotomy stability, in cleft lip and palate patients, using allogeneic bone graft. Dental Press J Orthod. 2013;18(5):84-90.

115. Stork JT, Kim RH, Regennitter FJ, Keller EE. Maxillary quadrangular le Fort i osteotomy: Long-term skeletal stability and clinical outcome. Int J Oral Maxillofac Surg. 2013;42(12):1533-46.

116. Cheung LK, Chua HDP, Hägg MB. Cleft maxillary distraction versus orthognathic surgery: clinical morbidities and surgical relapse. Plast Reconstr Surg. 2006;118(4):996-1008. Discussion 1009

117. Cheung LK, Chua HDP. A meta-analysis of cleft maxillary osteotomy and distraction osteogenesis. Int J Oral Maxillofac Surg. 2006;35(1):14-24.

118. Kwong Cheung L, Ser Pheng Loh J, Ho SMY. The early psychological adjustment of cleft patients after maxillary distraction osteogenesis and conventional orthognathic surgery: a preliminary study. J Oral Maxillofac Surg. 2006;64(12):1743-1750.

119. Chua HDP, Ho SMY, Cheung LK. The comparison of psychological adjustment of patients with cleft lip and palate after maxillary distraction osteogenesis and conventional orthognathic surgery. Oral Surg Oral Med Oral Pathol Oral Radiol. 2012;114(5 Suppl):S5-10.

120. Kloukos D, Fudalej P, Sequeira-Byron P, Katsaros C. Maxillary distraction osteogenesis versus orthognathic surgery for cleft lip and palate patients. Cochrane Database Syst Rev. 2018;8(8):CD010403

121. Chua HDP, Cheung LK. Soft tissue changes from maxillary distraction osteogenesis versus orthognathic surgery in patients with cleft lip and palate-A randomized controlled clinical trial. J Oral Maxillofac Surg. 2012;70(7):1648-58.

122. Thongdee P, Samman N. Stability of maxillary surgical movement in unilateral cleft lip and palate with preceding alveolar bone grafting. Cleft Palate Craniofac J. 2005;42(6):664-674.

123. Precious DS. Treatment of retruded maxilla in cleft lip and palate-orthognathic surgery versus distraction osteogenesis: the case for orthognathic surgery. J Oral Maxillofac Surg. 2007;65(4):758-61.
124. Hirano A, Suzuki H. Factors related to relapse after Le Fort I maxillary advancement osteotomy in patients with cleft lip and palate. Cleft Palate Craniofac J. 2001;38(1):1-10.

125. Watts GD, Antonarakis GS, Forrest CR, Tompson BD, Phillips $\mathrm{JH}$. Is linear advancement related to relapse in unilateral cleft lip and palate orthognathic surgery? Cleft Palate Craniofac J. 2015;52(6):717-23.

126. Hoffman GR, Brennan PA. The skeletal stability of one-piece Le Fort 1 osteotomy to advance the maxilla Part 2. The influence of uncontrollable clinical variables. Br J Oral Maxillofac Surg. 2004;42(3):226-30.

127. Haas Junior OL, Guijarro-Martínez R, de Sousa Gil AP, da Silva Meirelles L, Scolari N, Muñoz-Pereira ME, et al. Hierarchy of surgical stability in orthognathic surgery: overview of systematic reviews. Int J Oral Maxillofac Surg. 2019;48:1415.

128. Proffit WR, Turvey TA, Phillips C. The hierarchy of stability and predictability in orthognathic surgery with rigid fixation: An update and extension. Head Face Med. 2007;3(1):1-11.

129. Hoffman GR, Brennan PA. The skeletal stability of one-piece Le Fort 1 osteotomy to advance the maxilla Part 1. Stability resulting from non-bone grafted rigid fixation. Br J Oral Maxillofac Surg. 2004;42(3):221-5.

130. Kanno T, Mitsugi M, Hosoe M, Sukegawa S, Yamauchi K, Furuki Y. Long-term skeletal stability after maxillary advancement with distraction osteogenesis in nongrowing patients. J Oral Maxillofac Surg. 2008;66(9):1833-46.

131. Wolford LM, Karras SC, Mehra P. Considerations for orthognathic surgery during growth, Part 1: Mandibular deformities. Am J Orthod Dentofac Orthop. 2001;119(2):95-101.

132. Saltaji H, Major MP, Altalibi M, Youssef M, Flores-Mir C. Longterm skeletal stability after maxillary advancement with distraction osteogenesis in cleft lip and palate patients: A systematic review. Angle Orthod. 2012;82(6):1115-22.

133. Saltaji H, Major MP, Alfakir H, Al-Saleh MAQ, Flores-Mir C. Maxillary advancement with conventional orthognathic surgery in patients with cleft lip and palate: Is it a stable technique? J Oral Maxillofac Surg. 2012;70(12):2859-66.

134. Andersen K, Svenstrup M, Pedersen TK, Küseler A, Jensen J, Nørholt SE. Stability after cleft maxillary distraction osteogenesis or conventional orthognathic surgery. J Oral Maxillofac Res. 2015;6(2):e2

135. Serafin B, Perciaccante VJ, Cunningham LL. Stability of orthognathic surgery and distraction osteogenesis: options and alternatives. Oral Maxillofac Surg Clin North Am. 2007;19(3): 311-20, v.

136. Hirjak D, Reyneke JP, Janec J, Beno M, Kupcova I. Long-term results of maxillary distraction osteogenesis in nongrowing cleft: 5-years experience using internal device. Bratisl Lek Listy. 2016;117(12):685-90.

137. Gürsoy S, Hukki J, Hurmerinta K. Five-year follow-up of maxillary distraction osteogenesis on the dentofacial structures of children with cleft lip and palate. J Oral Maxillofac Surg. 2010;68(4):744-50

138. Chua HDP, Hgg MB, Cheung LK. Cleft maxillary distraction versus orthognathic surgery-which one is more stable in 5 years? Oral Surgery. Oral Med Oral Pathol Oral Radiol Endodontol. 2010;109(6):803-14.

139. Figueroa AA, Polley JW, Friede H, Ko EW. Long-term skeletal stability after maxillary advancement with distraction osteogenesis using a rigid external distraction device in cleft maxillary deformities. Plast Reconstr Surg. 2004;114(6):1382-92.

140. Yamaguchi K, Lonic D, Lo LJ. Complications following orthognathic surgery for patients with cleft lip/palate: A systematic review. J Formos Med Assoc. 2016;115(4):269-77.

141. Tabrizi R, Tumer K, Shafiei S, Rashad A. Can use of rigid fixation after consolidation increase stability in cleft patients fol- 
lowing distraction osteogenesis? J Oral Maxillofac Surg. 2018;76(6):1309-15.

142. Metalwala Z, Okunseri C, Fletcher S, Allareddy V. Orthognathic surgical outcomes in patients with and without craniofacial anomalies. J Oral Maxillofac Surg. 2018;76(2):436.e1-8.

143. Moran I, Virdee S, Sharp I, Sulh J. Postoperative complications following LeFort 1 maxillary advancement surgery in cleft palate patients: A 5-year retrospective study. Cleft Palate Craniofac J. 2018;55(2):231-7.

144. dos Santos Alves JM, de Freitas Alves BW, de Figueiredo Costa AC, Carneiro BGDS, de Sousa LM, Gondim DV. Cranial nerve injuries in Le Fort I osteotomy: a systematic review. Int J Oral Maxillofac Surg. 2018;10-2.

145. Ohrmann D, Hoyte-Williams PE, Chen PK-T. Update on complications in cleft orthognathic surgery. Curr Opin Otolaryngol Head Neck Surg. 2018;1

146. Eduardo Charles Pagotto L, de Santana Santos T, Juliana de Abreu de Vasconcellos S, Silva Santos J, Saquete Martins-Filho PR. Piezoelectric versus conventional techniques for orthognathic surgery: Systematic review and meta-analysis. J Cranio Maxillofacial Surg. 2017;45(10):1607-13.

Open Access This chapter is licensed under the terms of the Creative Commons Attribution 4.0 International License (http://creativecommons. org/licenses/by/4.0/), which permits use, sharing, adaptation, distribution and reproduction in any medium or format, as long as you give appropriate credit to the original author(s) and the source, provide a link to the Creative Commons license and indicate if changes were made.

The images or other third party material in this chapter are included in the chapter's Creative Commons license, unless indicated otherwise in a credit line to the material. If material is not included in the chapter's Creative Commons license and your intended use is not permitted by statutory regulation or exceeds the permitted use, you will need to obtain permission directly from the copyright holder. 